
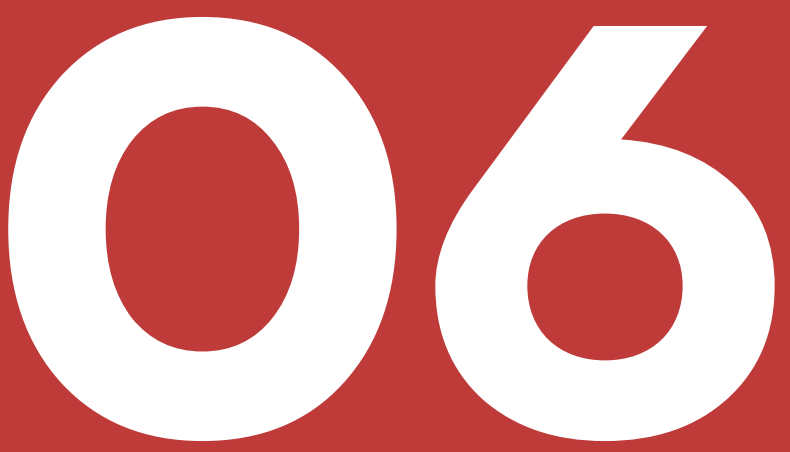

\title{
Midiendo la desigualdad y el nivel de riqueza: Una aplicación para Ecuador
}

Measuring inequality and the level of wealth: An application for Ecuador

FECHA DE RECEPCIÓN: 10/06/2021

FECHA DE APROBACIÓN: 21/08/2021

\section{cc) creative}




\section{Resumen}

Mercy Raquel Orellana Bravo'

Luis Santiago Sarmiento Moscoso²

Juan Pablo Sarmiento Jara ${ }^{3}$

En la actualidad, en la métrica del desarrollo económico se ha posicionado cada vez más el uso de los activos para representar la riqueza de los hogares. En este sentido, el objetivo de este artículo fue construir un índice alternativo, cuya característica principal es la utilización de activos que posee el hogar complementando, de esta manera, a los indicadores tradicionales basados únicamente en el ingreso o en el gasto. Por lo tanto, se trata de contribuir al debate académico acerca de la validez que tienen los índices de desarrollo para capturar realidades socioeconómicas complejas. Con la finalidad de valorar la robustez de los resultados, se construye un Índice de Riqueza para el Ecuador, utilizando dos encuestas distintas: la Encuesta Nacional de Empleo y Desempleo (ENEMDU), rondas 2011 y 2017 y la Encuesta de Ingresos y Gastos de los Hogares Urbanos y Rurales 2011-2012 (ENIGHUR), utilizando el Análisis de Componentes Principales (ACP) Policórico. Entre los principales hallazgos se evidencia que la acumulación de los activos ha aumentado con el tiempo, especialmente, en los hogares más pobres, pero, en una intensidad distinta en el área urbana y rural. Sin embargo, los indicadores de desigualdad respecto a este indicador no se han afectado; además, la tenencia de activos como laptops, vehículos y cobertura de servicios básicos, ponderan más en la construcción del índice de riqueza en los hogares. Al comparar el nivel de riqueza según la metodología policórica y el nivel de ingresos percápita, ubica en una mejor posición de bienestar a los hogares con la metodología propuesta del nuevo indicador, especialmente, en el quintil más pobre y más rico, aunque se destaca que se mantiene importantes niveles de desigualdad, problemática estructural en la realidad socioeconómica de los hogares ecuatorianos.

Palabras claves: Activos, análisis policórico, indicadores, riqueza,

Códigos JEL: C81; D31; J10.

1 Universidad de Cuenca · mercy.orellana@ucuenca.edu.ec · Cuenca - Ecuador

2 Universidad del Azuay • santiago.sarmiento@uazuay.edu.ec· Cuenca - Ecuador

3 Universidad de Cuenca · juan.sarmiento@ucuenca.edu.ec • https://orcid.org/0000-0003-2841.

7054 - Cuenca - Ecuador 


\section{Abstract}

urrently, the metric of economic development has increasingly positioned the use of assets to represent household wealth. In this sense, the objective of this article is to construct an alternative index whose main characteristic is the use of assets owned by the household, thus complementing the traditional indicators based solely on income or expenditure. Therefore, it is about contributing to the academic debate about the validity of development indices to capture complex socioeconomic realities. In order to assess the robustness of the results, a Wealth Index is constructed for Ecuador, using two different surveys: the National Survey of Employment and Unemployment (ENEMDU), rounds 2011 and 2017 and the Survey of Income and Expenditure of the Urban and Rural Households 20112012 (ENIGHUR), using the Principal Component Analysis (PCA) Polychoric. Among the main findings, it is evident that the accumulation of assets has increased over time, especially in the poorest households, but at a different intensity in urban and rural areas. However, the inequality indicators regarding this indicator have not been affected; In addition, the possession of assets such as laptops, vehicles and coverage of basic services weigh more in the construction of the household wealth index. When comparing the level of wealth according to the polychoric methodology and the level of per capita income, it places households in a better position of well-being with the proposed methodology of the new indicator, especially in the poorest and richest quintile, although it is highlighted that significant levels of inequality remain, a structural problem in the socio-economic reality of Ecuadorian households.

Keywords: Assets, indicators, polychoric analysis, wealth.

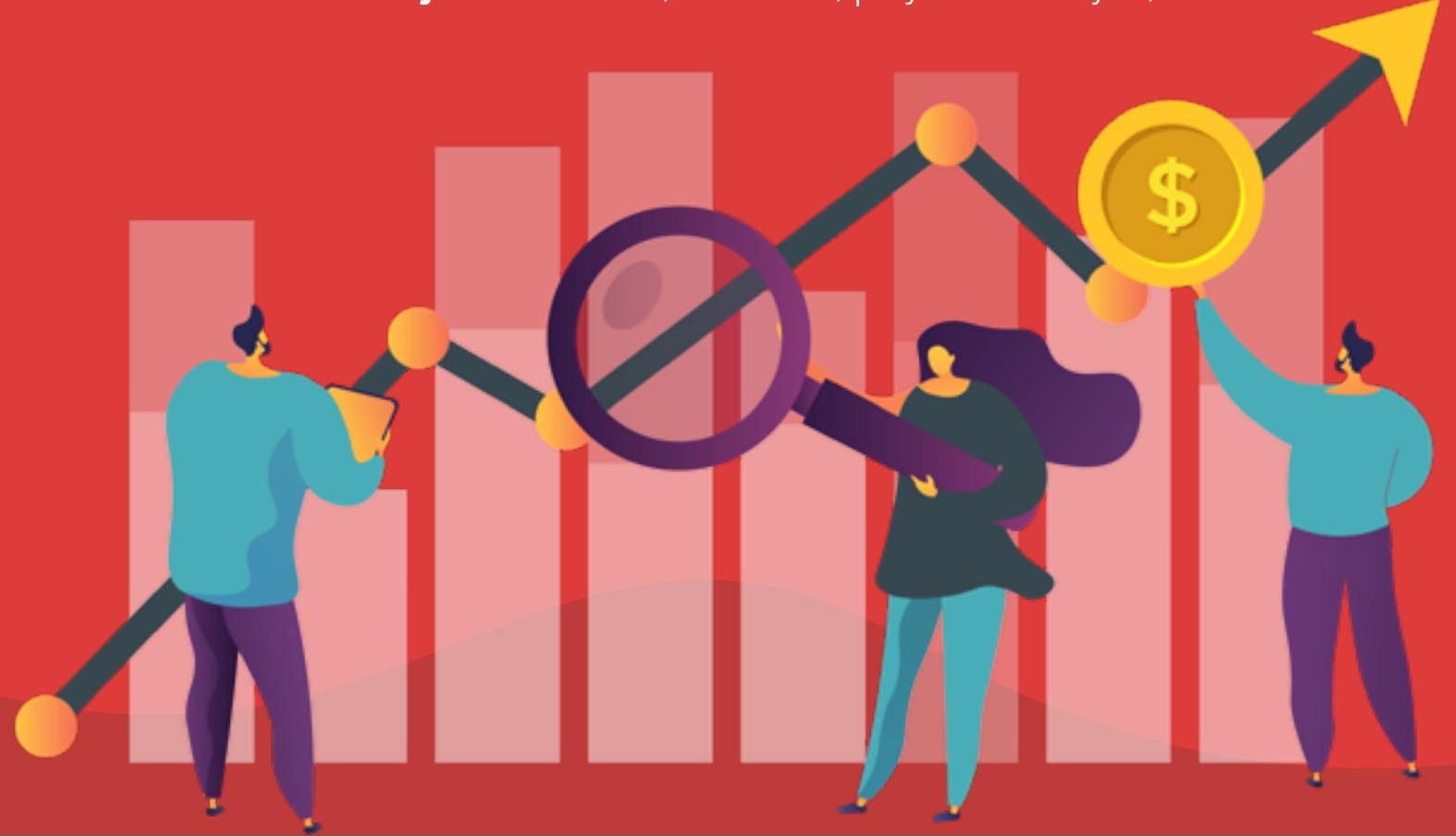




\section{Introducción}

no de los principales objetivos de la política de desarrollo sostenible, según las Naciones Unidas en 2015, es mejorar el bienestar de los individuos, así como fomentar la resiliencia económica y social de las personas que se encuentran en situación de vulnerabilidad. Las medidas tradicionales mediante las cuales los investigadores han evaluado el bienestar y el nivel socioeconómico se reflejan en medidas basadas en unidades monetarias del ingreso laboral o por el lado de los gastos, datos que son recogidos mediante las encuestas de ingresos salariales y/o de gasto o consumo (Alkire, 2013; Bourguignon, y Chakravarty; 2003); sin embargo, estas medidas pueden generar interpretaciones primitivas al incorporar una o pocas dimensiones en el cálculo de un indicador (Lambert, 1968: Paraje, 2008, Ward, 2014; Anghel et al.; 2018). En este sentido, una medida de bienestar coherente con este punto de vista incorporaría otras dimensiones además de las monetarias y encarnaría el amplio conjunto de capacidades de un hogar representados por la acumulación de activos por ejemplo Sen (1999), Sahn y Stifel (2003).

Estas medidas pueden ser problemáticas por varias razones. En primer lugar, en países en desarrollo o subdesarrollados tienden a existir variaciones estacionales significativas entre las fuentes de ingresos (Amek et al., 2015); mientras que, los gastos de consumo, si bien tienden a ser consistentes en las predicciones de los ingresos permanentes, generalmente, solo capturan las transacciones monetarias y no se registra el consumo de bienes y servicios producidos en el hogar, por lo tanto, solo recogen una instantánea a corto plazo del verdadero bienestar de un hogar (Friedman, 1957).

Complementariamente, se evidencian importantes sesgos en la medición de los ingresos, ya que los hogares suelen reportar únicamente sus ingresos laborales, sin considerar otros componentes como la producción doméstica y el tiempo de ocio. Además, resulta difícil cuantificar los ingresos obtenidos en el sector agrícola, en el sector informal, así como los ingresos por envío de remesas, cuyo peso en los trabajadores son representativos en países subdesarrollados (Montgomery et al., 2000; Rutstein y Johnson, 2004). 
Por otro lado, el gasto de consumo generalmente captura las transacciones realizadas en el mercado e ignora el valor de las transacciones no monetarias que incluyen bienes de consumo, que tienden a aumentar el bienestar (Ward, 2014). Por lo tanto, las medidas tradicionales basadas en el ingreso o en el gasto pueden capturar solo una dimensión del nivel de bienestar, de ahí que surge la necesidad de construir métodos alternativos para analizar el bienestar de la población, mediante la acumulación de riqueza como la posesión de bienes y, con ello, facilitar y completar las comparaciones de bienes (Deaton y Zaidi, 2002).

En la última década, los economistas del desarrollo han defendido cada vez más el uso de la tenencia de activos para establecer medidas complementarias del nivel de bienestar de los hogares, cuyos índices se derivan de una larga lista de posesiones domésticas, de acceso y calidad de servicio, por ejemplo, los básicos como agua, luz y eliminación de excretas (Amek, et al.; 2015; Balen, et al.; 2010; Howe, et al.; 2009).

Tal es así que, se ha establecido que la propiedad de activos es más fácil y confiable de medir en comparación a los ingresos o gastos del consumidor (Howe et al., 2009), ya que al ignorar el capital financiero pueden considerarse adecuadamente como complementos a las medidas tradicionales, ampliando la comprensión de los aspectos vinculados al bienestar de la población (Amek et al., 2015; Carter y May, 2001; Filmer y Pritchett, 2001) e incluso como indicativo de las capacidades o libertades del hogar (Sen, 1999). Por lo tanto, el uso de los activos domésticos puede proporcionar una imagen holística del bienestar, permitiendo un análisis más representativo del impacto de las políticas redistributivas; además, según Moser y Felton (2007), los activos de los hogares suelen ser de naturaleza duradera, reflejando de mejor manera los estándares de vida a largo plazo en comparación a los ingresos o gastos.

La información y las mediciones acerca de la posesión de activos dentro de los hogares y a través del estado socioeconómico es fundamental para las intervenciones de políticas dirigidas a los más pobres (Booysen et al., 2008; Filmer y Pritchett, 2001; Montgomery et al., 2000; Schellenberg et al., 2003). En este contexto, el objetivo de la presente investigación es determinar y analizar el efecto de distintas variables en el bienestar de 2011 y 2017 en Ecuador, a través de la construcción de un índice de riqueza. Para ello, se propone utilizar como metodología el análisis de componentes principales (ACP) policórico, 
técnica que a diferencia de otras permite utilizar variables discretas y/o continuas basadas en los activos de los hogares.

Estos activos se calculan como una suma ponderada de indicadores categóricos no observables, con pesos denominados cargas factoriales, permitiendo, además, analizar las tendencias de la posesión de bienes del hogar y la interacción espacio tiempo. Por lo tanto, la correlación policórica asume que cada una de las variables está influenciada por una variable latente, normalmente distribuida y permite estimar la correlación entre ellos a través de la máxima probabilidad (Kolenikov y Angeles; 2004).

El artículo está organizado de la siguiente manera: primero se presenta la revisión de literatura relevante sobre el tema; en segundo

lugar, se detalla la metodología aplicada; en tercer lugar, se analizan los principales datos descriptivos de las variables empleadas y los resultados estimados para, finalmente, detallar las conclusiones de la investigación. 


\section{Revisión de Literatura}

En los últimos años, las medidas basadas en la propiedad de activos de los hogares y otras formas de capital familiar se han utilizado ampliamente para las comparaciones de bienestar. Partiendo de análisis concretos, Deaton y Zaidi (2002) estiman un indicador simple en base al consumo para examinar los efectos de la provisión de bienes públicos y, con ello, aproximarse a una medida que represente el bienestar de los hogares. Onwujekwe, et al. (2006) estiman un conjunto de indicadores de bienestar calculados mediante índices simples y compuestos, con el objetivo de validar la robustez de los resultados, determinando que no se evidencia un número óptimo de elementos en los que se debería incluir para construir un indicador de bienestar y, más bien, incluir un importante número de variables, que puede conducir a problemas de confiabilidad en las variables constituyentes. En este sentido, Montgomery et al. (2000) destacan que dada las limitaciones de información precisa de ingresos o gastos en las encuestas socioeconómicas de los países en desarrollo, los investigadores interesados en medir el bienestar de los hogares no tenían otra alternativa que depender de indicadores indirectos simples, por lo tanto, surge la necesidad de incorporar variables proxies que no se han analizado sistemáticamente.

La propuesta y construcción de medidas de bienestar económico basadas en la propiedad de los bienes del hogar, fue una aplicación pionera de Filmer y Pritchett (2001) quienes, al no poseer datos de ingresos o de gastos, construyeron un índice de riqueza para usarlo como proxy del estado socioeconómico del hogar en la predicción de la matrícula educativa en los estados de la India. Complementariamente, Filmer y Pritchett (2001) evidenciaron que el índice estimado resultó confiable y robusto; así, a partir de esta aplicación se ha utilizado no solo dentro del ámbito económico sino en otros campos multidisciplinares como el de la salud y de la educación. Por ejemplo, Bollen et al. (2002) analizan las consecuencias de usar diferentes proxis del bienestar medido por la riqueza de la población, como la tenencia de bienes de consumo duraderos, sobre su impacto en la predicción de la fertilidad para Ghana y Perú; además, Fay et al. (2005), Sahn y Stifel (2003), Sastry (2004) consideran que la alternativa basada en la tenencia de activos es un predictor a largo plazo de la pobreza en variables como la salud infantil, la nutrición y la tasa de mortalidad. 
Amek et al. (2015), construyen un índice de bienestar en función de los activos y características de los hogares, como la fuente de agua potable, el combustible para cocción y la ocupación del jefe del hogar. Para ello, aplican la Encuesta Demográfica y de Salud de Kenya, de la cual, deducen que la brecha en este índice entre los quintiles más pobres y más ricos incrementó en $6 \%$ en el periodo de estudio; además, el análisis espacial reveló que el aumento en los hogares con mayor poder adquisitivo se centró en las regiones del sur del país. Utilizan ACP policórico para estimar un indicador del bienestar de la población (estatus socioeconómico), incluyendo variables como ocupación del jefe del hogar, fuente principal de agua potable, uso de combustible para cocinar, propiedad de bienes domésticos (lámpara, linterna, sofá, radio, bicicletas y televisión) y posesiones de bienes agrícolas; su indicador explicó el $47.3 \%$, de la varianza, mostrando resultados que son comparables con las estimaciones efectuadas con el análisis por correspondencia múltiple.

Sahn y Stifel (2000) estiman una medida de bienestar como resultante de un análisis factorial de diversas características del hogar, bienes duraderos y educación de los jefes de hogar, obteniendo una mejora en el nivel de riqueza de la población justificado, principalmente, por las mejoras en las zonas rurales.

Por otro lado, Ward (2014) examina tres medidas de la riqueza de los activos de los hogares que caracterizan las dimensiones del bienestar basados en los ingresos tradicionales o medidas basadas en el gasto, ya que se basa en la valoración subjetiva del capital de los hogares y se considera una medida directa fácilmente interpretable. Las dos medidas restantes son índices construidos a partir de la ponderación de factores basados en la metodología de componentes principales de la matriz de correlación de factores poliseriales. A partir de ello, calcula un indicador de riqueza para medir el bienestar mediante la metodología antes mencionada para el caso de China, agrupando las variables utilizadas en cuatro dimensiones; la primera dimensión denominada capital del hogar, incluye la antigüedad de la vivienda, número de cuartos, fuente de suministro de agua, de electricidad, material del techo, de las paredes y del piso; la segunda dimensión corresponde al capital físico no productivo, que incluye variables como posesión de bicicletas, número de autos y número de motos; la tercera agrupa el capital de bienes 
durables, considerando el número de radios, lavadoras, televisores, aire acondicionado, cámaras; finalmente, está el capital productivo físico que incluye el número de tractores, de irrigadores, de bombas de agua, equipo de cocina, de coser, de carpintería etc. Entre los principales resultados se registra un incremento de la posesión de activos, pero, con importantes diferencias entre las áreas urbana y rural, ya que en las últimas, la acumulación de activos creció más rápido que en las primeras.

En distintas investigaciones buscan construir un índice de riqueza aplicando la metodología de componentes principales policórico, destacando los estudios de Balen et al. (2010), quienes utilizan variables de posesión de activos así como de características del hogar y servicios de básicos. En este contexto, Luby y Halder (2008), Schellenberg et al. (2003) utilizan, además, variables de las características individuales como la educación del jefe del hogar, que determinan de manera más significativa el nivel de bienestar de la población.

Para el caso ecuatoriano es muy limitada la literatura sobre la estimación de un indicador de riqueza, sin embargo, se evidencia el estudio de Moser y Felton (2007), quienes construyen un índice de riqueza por componentes principales basado en un conjunto de datos de panel longitudinal de la ciudad de Guayaquil, concentrando el análisis en indicadores como capital físico, productivo, humano y social; concluyen que una comprensión integral de la acumulación de activos del hogar complementa los datos de ingresos y ayuda a identificar por qué algunos hogares son más móviles que otros; es decir, se trata de entender cómo algunos hogares salen de la pobreza con éxito mientras que otros fracasan; finalmente, destacan que los bienes duraderos productivos como los automóviles representan un flujo de ingresos actual o potencial. Sus resultados muestran que los bienes del hogar durables y el capital humano, tienen una mayor ponderación y significatividad en el índice de riqueza. 


\section{Metodología}

Existe una vasta literatura del uso de variables discretas en los métodos multivariados, uno de estos es el Análisis de Componentes Principales (ACP). El ACP permite reducir un grupo de variables a partir de la creación de nuevas variables que son combinaciones lineales de esas variables originales (Abeyasekera; 2005). La primera versión del análisis de componentes principales fue introducida en Pearson (1901). El objetivo de esta técnica es resumir un grupo de variables en un grupo más pequeño. El ACP toma los principales vectores propios de la descomposición de la matriz de correlación o covarianza, lo que describe las combinaciones lineales de las variables que contienen la mayor varianza del conjunto; además, los vectores propios son ortogonales entre sí.

Uno de los supuestos del ACP es que las variables son continuas y presentan una distribución normal. La creación de índices a partir del ACP para las ciencias sociales es una práctica común, sin embargo, la naturaleza de las variables puede generar problemas en las estimaciones, sobre todo, porque la obtención de variables continuas se vuelve más complicada. Por ejemplo, las variables que dan cuenta de la riqueza de los hogares típicamente miden la posesión de activos del hogar, las características de la vivienda y las características del jefe del hogar; lo que suele incluir variables de todo tipo como numéricas, continuas, dicotómicas, entre otras (Abeyasekera; 2005, Amek, et al. 2015 y Boosen, et al.; 2008 ).

En este sentido, se explica a continuación la metodología empleada. En primer lugar, dado que las variables discretas violan el supuesto de distribución Gaussiana del ACP, el análisis será sesgado; en estos casos, se recomienda utilizar un ACP Policórico, basado en el coeficiente de correlación policórico (Kolenikov S, Angeles G (2004), s. f.; Olsson, 1979; Rigdon y Ferguson, 1991).

Conceptualmente, para establecer una correlación policórica se utilizan los indicadores ordinales de las variables, las cuales, se suponen latentes en las categorías construidas. (Dong et al., 2014). Sean $y_{1}$ y $y_{2}$ dos variables con $k_{1}$ y $k_{2}$ y categorías respectivamente, las mismas que 
se obtienen de discretizar las variables continuas latentes $y_{1}{ }^{*}$ y $y_{2}{ }^{*}$ de acuerdo a un set de umbrales $b_{(j, 1)}, \ldots, b_{\mathrm{j}, \mathrm{m} \mathrm{j}-1}$ para $j=1,2$ :

$$
y_{j}=\left\{\begin{array}{l}
q \text { si } b_{j, q-1}<y_{j}^{*}<b_{j, q}, \text { para } q=1, \ldots, m_{j-1} \\
0 \text { en otro caso }
\end{array}\right\}
$$

$$
\text { Donde } b_{j, 0}=-\infty, b_{j, m_{j}}=+\infty \text {. }
$$

La correlación policórica es la correlación para las variables continuas latentes y implícitas en las variables ordinales observadas $y_{1}$ y $y_{2}$ (Dong et al., 2014).

$$
\left(\begin{array}{l}
y_{1}^{*} \\
y_{2}^{*}
\end{array}\right) \sim N\left(0,\left(\begin{array}{ll}
1 & \rho \\
\rho & 1
\end{array}\right)\right),-1 \leq \rho \leq 1
$$

Donde $\operatorname{Cov}\left(y_{1}^{*}, y_{2}^{*}\right)=\rho$.

Asumiendo una distribución normal bivariada con media cero y varianza unitaria para las variables latentes $y_{1}$ * y $y_{2}$ * (Olsson, 1979), y dada la función de verosimilitud de los coeficientes de correlación policóricos, que son estimados usando las variables observadas $y_{1}$ y $y_{2^{\prime}}$ la función de distribución acumulada sería:

$$
\Phi_{2}(s, t ; \rho)=\int_{-\infty}^{s} \int_{-\infty}^{t} \frac{1}{2 \pi \sqrt{1-\rho^{2}}} \exp \left[-\frac{1}{2\left(1-\rho^{2}\right)}\left(u^{2}-2 \rho u v+v^{2}\right)\right] d u d v
$$


Dado los umbrales antes definidos; luego la probabilidad en la celda es:

$$
\begin{gathered}
\pi(i, j, \rho, b)=\operatorname{Prob}\left[y_{1}=i, y_{2}=j\right]= \\
=\Phi_{2}\left(b_{1, i}, b_{2, j} ; \rho\right)-\Phi_{2}\left(b_{1, i-1}, b_{2, j} ; \rho\right)- \\
-\Phi_{2}\left(b_{1, i}, b_{2, j-1} ; \rho\right)+\Phi_{2}\left(b_{1, i-1}, b_{2, j-1} ; \rho\right)
\end{gathered}
$$

Asumiendo que las observaciones son aleatorias e idénticamente distribuidas (i.i.d.), la estimación de verosimilitud busca maximizar el logaritmo de la función de verosimilitud, dado por:

$$
\ln L=\sum_{i=1}^{N} \ln \pi\left(y_{i, 1}, y_{i, 2} ; \rho, b\right)
$$

Si se maximiza sobre $p$ y $b$, se obtiene la correlación policórica de $y_{1}$ y $y_{2}$. Combinando los pares de correlaciones policóricas estimadas, se construye la matriz de correlación de los datos observados, para luego ser usados al realizar ACP'1.

\section{Datos}

Siguiendo a la mayoría de investigaciones para el cálculo del índice de riqueza, en este trabajo se utilizan variables de características del jefe de hogar, tenencia de activos del hogar y servicios básicos. Los datos provienen de la Encuesta Nacional de Empleo y Desempleo de Ecuador (ENEMDU) para 2011 y 2017, años de interés dado que se registraron los mayores niveles de crecimiento económico, tanto para el Gobierno de Rafael Correa como de Lenin Moreno. Es decir, en 2011, el nivel de crecimiento de la economía fue del 7,86\%; mientras que, en 2017 fue de 2,8\% (Banco Mundial, 2021).

$\overline{1}$ En el presente artículo, se utiliza el comando polychoricpca de STATA 15. 
El objetivo de la encuesta mencionada es estimar la situación del empleo en el país, la caracterización del mercado de trabajo, la actividad económica y las fuentes de ingresos de la población. La cobertura de la ENEMDU es a nivel nacional, contando en 2011 con una muestra de 18776 hogares y, en 2017, con 30023. Dentro de las variables que caracterizan al hogar se dispone del nivel de instrucción del jefe del hogar; en posesión de activos se emplea: televisores LCD, laptops, refrigeradoras, lavadoras, microondas y vehículos; finalmente, la variable que considera la cobertura de servicios básicos es el sistema de eliminación de excretas.

Con el objetivo de contrastar las estimaciones y comprobar la robustez de los resultados, también se ha utilizado la última encuesta disponible la Encuesta Nacional de Ingresos y Gastos de los Hogares Urbanos y Rurales (ENIGHUR) 2011; esta encuesta ofrece una visión específica y más detallada del presupuesto familiar en cuanto a la estructura, monto y distribución del ingreso y del gasto de los hogares en Ecuador a partir de las características socioeconómicas y demográficas de los miembros del hogar, posesión de activos, así como de las características de la infraestructura de la vivienda y el equipamiento. Se trabaja con todos los hogares disponibles en la encuesta que suman 39617 hogares.

En la Tabla 1 se observan los principales descriptivos de las variables empleadas para la construcción del índice. En resumen, se observa una importante asimetría en la posesión de activos, caracterización del jefe del hogar y cobertura de servicios básicos, mejorando la situación entre el periodo de análisis. Un importante número de hogares no poseen vehículos, laptops o televisores LCD. En 2011, a nivel de quintiles las mayores diferencias entre el quintil 1 y 5 se da en la posesión de televisores LCD y laptops, pues, el $23 \%$ de las personas del quintil 5 tienen un LCD en comparación al 1\% del quintil 1. El $49 \%$ de los hogares del quintil 5 tienen un microondas en comparación al $4 \%$ del quintil más pobre que indican poseer uno. El $38 \%$ de los hogares del quintil más rico tiene un vehículo en comparación al 6\% del quintil 5. En 2017, se registra una menor diferencia existente en los niveles de instrucción entre el quintil más pobre y el más rico, así como en la tenencia del resto de activos y cobertura de servicios básicos. 
De manera específica, en 2011, se observa que a nivel de educación de los jefes del hogar, un $51 \%$ tiene educación primaria y solo un 13\% educación superior; mientras que, para 2017 el nivel de instrucción mejoró, pues, el 33\% de los jefes del hogar tienen educación secundaria y el $18 \%$ aproximadamente logró obtener educación superior. A nivel de quintiles, en 2017 un 46\% de las personas del quintil 5 tiene educación superior, en comparación al 3\% de las personas del quintil más pobre. Respecto a la posesión de LCD, en 2011 apenas un 5,21\% de los hogares tenían un LCD y, en 2017, este bien estaba en posesión del $26 \%$ aproximadamente de los hogares; de igual manera, existe una amplia disparidad entre el quintil más bajo y alto en la tenencia de este bien. Se evidencia que prácticamente los hogares tienen como máximo cinco televisores de estas características. Respecto a las unidades familiares que tienen refrigeradora llega al $73 \%$ en 2011 y un 60\% en 2017, con una importante diferencia entre niveles de ingresos, por ejemplo, en 2017 el $92 \%$ de los hogares del quintil 5 tienen refrigeradora frente al $60 \%$ de las personas del quintil 1.

La posesión de laptops, lavadoras, microondas y vehículos también reflejan un comportamiento heterogéneo entre niveles de ingresos. Por ejemplo, los hogares que pertenecen al quintil 5 en un porcentaje no mayor al 42 por ciento en promedio no tienen cualquiera de estos bienes; mientras que, los del quintil 1 más del $90 \%$ no poseen los activos antes indicados. Las personas del quintil 5 tienen como máximo cinco vehículos en 2017 y las personas del quintil 1 como máximo uno. Por último, en cuanto al acceso a servicios públicos entre el periodo de análisis no existe un avance significativo, por ejemplo, en 2011, el 55\% tenía servicio de alcantarillado, en 2017 esta cifra llegó al 64\%. Entre quintiles de ingreso la diferencia es notoria, dado que más del $80 \%$ de los hogares más ricos tienen acceso a este servicio; mientras que, las personas del quintil 1, solo el $42 \%$ tienen alcantarillado y el $12 \%$ no tienen ningún tipo de sistema de eliminación de excretas. 
Tabla 1: Datos descriptivos de las variables estimadas a nivel nacional, por quintiles de ingreso².

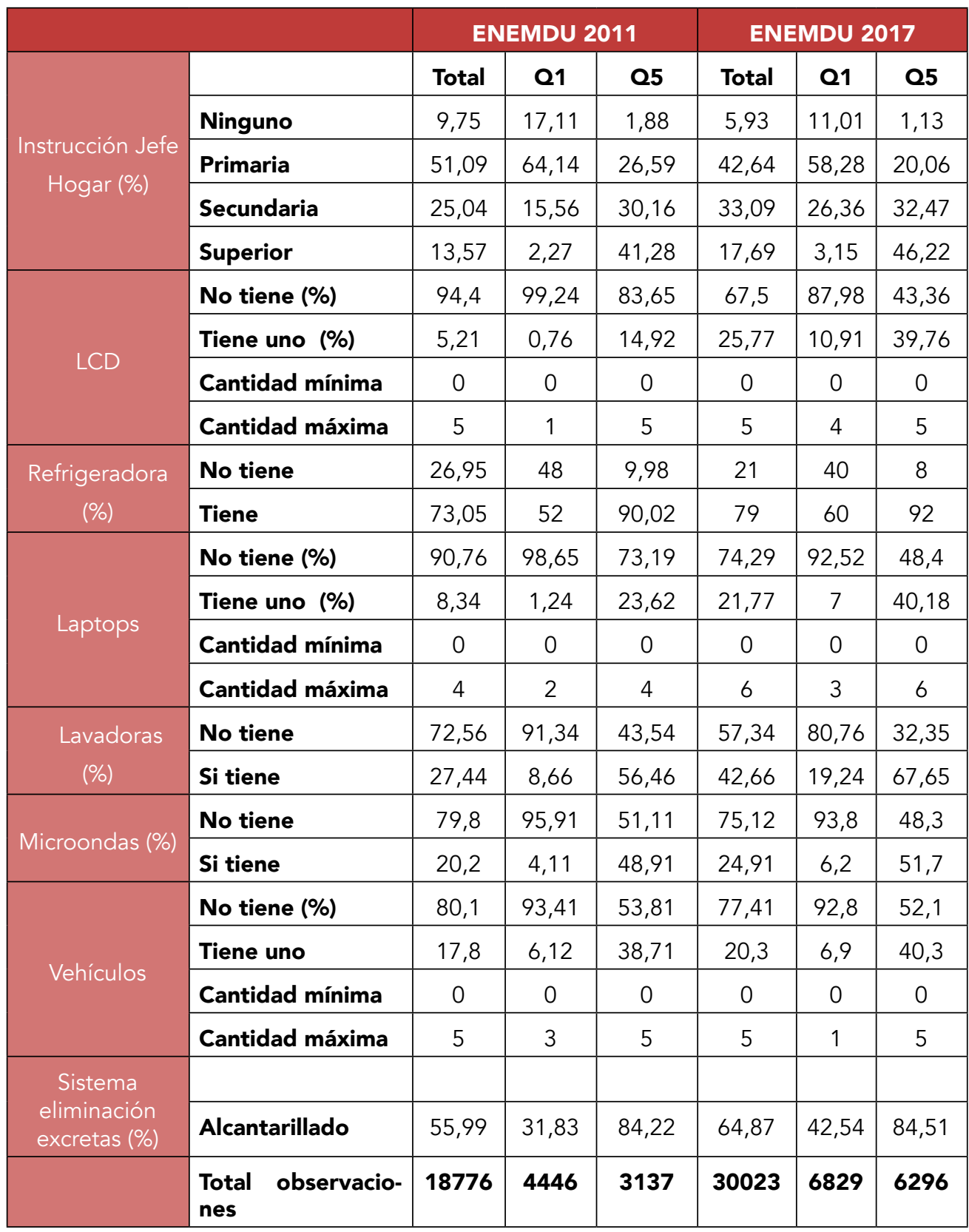

Fuente: ENEMDU 2011 y 2017.

2 Se considera las categorías con mayor peso porcentual de cada bien. 
Complementariamente, se presenta el comportamiento de las variables con sus respectivas categorías utilizadas para la estimación del indicador de riqueza para los hogares ecuatorianos, esto a nivel de toda la población, por quintiles de ingreso (Tabla A1) y por área de localización (urbana o rural) según cada una de las encuestas empleadas (De la Tabla A2 a la A4). En estas tablas se observa el número de bienes que posee cada hogar, que va desde 0 hasta el máximo número registrado en los datos ${ }^{3}$. Entre los resultados más relevantes a nivel nacional (Tabla A.1) se encuentra que, aproximadamente, el $6 \%$ de los jefes del hogar no tiene ningún nivel de educación, así también a nivel de quintiles. En cuanto al comportamiento de la categoría educación superior, es una de las categorías con mayor dispersión entre el quintil más alto y el más bajo.

En cuanto a las variables de activos del hogar, han cambiado, pues, para el año 2011, los hogares que no poseía televisor LCD llegaban al $95 \%$, dicha cifra disminuye a $67.5 \%$ para el año 2017 , resultado que podría justificarse por la disminución de los precios, facilitando la adquisición de estos bienes. Otra variable que presenta una heterogeneidad importante es la posesión de laptops; mientras que, la tenencia del resto de activos de hogar se mantiene sin variaciones significativas a lo largo del tiempo y entre quintiles.

Al comparar el porcentaje de posesión de bienes y cobertura de servicios a nivel nacional con las áreas urbanas y rurales se identifica la brecha regional existente; por ejemplo, se destaca las disparidades en educación secundaria y superior. Para 2017, las brechas de posesión entre urbano y rural de la mayoría de los bienes analizados se reducen como se observa en la tabla A.4. Por lo tanto, entre 2011 y 2017, la evolución más desigual entre quintiles altos y bajos se da en bienes como televisores LCD, computadoras portátiles y vehículos, además de la instalación de alcantarillado como sistema eliminación de excretas y el nivel de educación del jefe de hogar.

3 Por ejemplo, hay hogares que no tienen ningún LCD o ninguna laptop y otras tienen hasta ocho LCD o seis laptops. 


\section{Resultados}

En cuanto al indicador construido, se estimó utilizando las ponderaciones del primer componente que recoge más del $50 \%$ de la varianza de las variables utilizadas; posteriormente, se estandarizó el indicador, siendo uno el valor máximo del índice de riqueza y cero reflejando la carencia de activos. Así también, debido a las persistentes disparidades territoriales, económicas y sociales reportadas en Ecuador (Mendieta y Pontarollo, 2015; Orellana et al., 2016)it allows identifying clusters of cantons characterised by similar spatial patterns that can be interpreted as convergence clubs because they represent areas with similar initial conditions in the "basin of attraction" that, according to economic theory, converge to a common steady state equilibrium. InThe results highlight that a convergence process is present, but it involves the cluster of most developed cantons. This opens various policy implications related to i, el área (urbano o rural) de ubicación de los hogares es incorporado en el análisis del comportamiento del índice de riqueza propuesto.

En la Tabla 2 se muestra el listado de las variables utilizadas con sus respectivos pesos estimados según la metodología del ACP policórico. Estos se pueden interpretar como el «tamaño» de la variable latente subyacente, es decir, proporciona una medida del efecto de cada variable en el bienestar de un hogar, representado por el índice de riqueza estimado (Ward, 2014). Las variables con ponderaciones más altas contribuyen de mejor manera al indicador de riqueza del hogar en comparación a variables con ponderaciones más bajas; mientras que, las variables con ponderaciones negativas resta valor a la riqueza de las familias. Para la presente investigación se ha considerado al primer componente principal, dado que la varianza explicada para el año 2011 y 2017 es mayor al 50\%, en las dos bases utilizadas (Uriel y Aldás, 2005).

Las dimensiones empleadas se recogen mediante las variables de las características del jefe de hogar, tenencia de activos del hogar y servicios básicos. De acuerdo al peso reportado de cada una de las variables se evidencia que la dimensión activos del hogar tiene mayor incidencia en el índice como, por ejemplo, la posesión de vehículos y laptops al igual que el sistema de eliminación de excretas. Según la ENEMDU 2011, por ejemplo, el peso asignado por poseer una televisión 
LCD es de 0,65 respectivamente ${ }^{4}$; según la ENEMDU de 2017 tener un vehículo y la posesión de un microondas ocupan la mayor ponderación con 0,41 y 0,49 respectivamente. Además la posesión de una laptop, también influye significativamente según las diferentes encuestas y el periodo de tiempo considerado (Ver Tabla 2).

Por otro lado, se presenta una importante variabilidad de las ponderaciones en la categoría de educación del jefe del hogar, dado que, si pasa de no tener educación a tener educación secundaria, la puntuación del indicador mejora en $0.8^{5}$, lo que muestra que las políticas dirigidas en aumentar los años de educación, lograrían mejorar los niveles de vida de los hogares, dato que sobresale al considerar que el $63 \%$ de jefes de hogar del quintil 1 no poseen educación secundaria.

Los resultados son, en general, robustos entre las dos encuestas utilizadas y a lo largo del tiempo; así, contrastando los pesos obtenidos entre 2011 y 2017 se puede evidenciar que no existe mayor diferencia en la puntuación obtenida de las categorías correspondientes a las variables de posesión de activos como lavadoras, refrigeradoras, educación del jefe del hogar y respecto a las características de la vivienda como el sistema de eliminación de excretas. Sin embargo, se registran importantes cambios en las ponderaciones de variables como posesión de LCD, reasignando un peso mucho menor en 2017 en comparación al 2011. Esto podría estar justificado, como se mencionó anteriormente, por el incremento de la demanda en estos productos; de igual manera, existe una caída considerable en los pesos asignados en la posesión de portátiles.

Considerando las variaciones en las puntuaciones, cuando se toma como referencia la tenencia de un activo del hogar respecto a no tenerlo, se destacan variables como el sistema de eliminación de excretas y el nivel de educación secundaria del jefe del hogar. En este sentido, no tener el servicio público de alcantarillado frente a tenerlo, la ponderación cambia de -0,66 a 0,18 en 2017; mientras que, no poseer un nivel de instrucción a tener un nivel de educación secundaria, la ponderación varía de $-0,62$ a 0,13 respectivamente. Sin embargo, las menores variaciones se registran en poseer un vehículo y en la posesión de LCD.

$4 \quad$ Para comprobar la robustez de los resultados se compara con los datos de la ENIGHUR, 2011, en donde por ejemplo el peso asignado en tener una LCD es de 0,61.

$5 \quad$ Este valor corresponde a la diferencia del peso de no tener educación $(-0,58)$ y tener educación secundaria $(0,21)$. 
Los hallazgos encontrados en Amek, et al. (2015), Booysen et al. (2008) coinciden parcialmente con los resultados obtenidos en este trabajo, puesto que ponderan al indicador de riqueza en mayor medida a la posesión de activos del hogar como los televisores y asignan un menor peso a bienes de consumo masivo como lavadoras y a los servicios básicos como el sistema de eliminación de excretas. Tal es así que, por ejemplo, la tenencia de televisores pondera 1,6 puntos al indicador frente a 0,03 que corresponde abastecerse de agua potable por red pública. Sin embargo, al contrario de los resultados obtenidos en esta investigación, la tenencia de bienes como refrigeradoras tiene un importante peso en la construcción de su índice de riqueza; mientras que, la posesión de un vehículo no. En cuanto a la varianza explicada en el primer componente, el valor en dichos estudios bordea el $43 \%$.

A esto se suman los resultados de Moser y Felton (2007), quienes resaltan el peso, en el índice de riqueza, de la posesión de bienes como son la tenencia de televisores, computadoras y autos, cuyas ponderaciones oscilan en 0,73; 0,79 y 0,83, respectivamente. En este sentido, McKenzie (2005) agrega que la fuente de energía eléctrica que posee una vivienda y la posesión de un vehículo, tal como se comprueba en este trabajo, son factores importantes en la medición de riqueza y bienestar de un hogar, reportando además que la desigualdad de Gini ${ }^{6}$ en el consumo de activos es menor respecto a la desigualdad medida según los ingresos de los hogares.

$6 \quad$ El índice de Gini mide hasta qué punto la distribución del ingreso o consumo entre individuos u hogares se aleja de una distribución perfectamente equitativa, es decir, mide el grado de concentración en la distribución de ingreso o de consumo per cápita sobre el total de hogares. Se encuentra entre 0 y 1 , siendo cero la máxima igualdad (todos los individuos tienen los mismos ingresos) y 1 la máxima desigualdad (todos los ingresos los tiene un solo individuo) (IISEC, 2017). 
Tabla 2. Variables incluidas y pesos obtenidos del primer componente bajo la técnica de análisis de componentes principales policórico

\begin{tabular}{|l|c|c|}
\hline & ENEMDU 2011 & ENEMDU 2017 \\
\hline Valor propio & 4,863 & 4,722 \\
\hline Varianza explicada & 0,608 & 0,590 \\
\hline $\begin{array}{l}\text { Instrucción del jefe del } \\
\text { hogar }\end{array}$ & & \\
\hline Sin educación & $-0,588$ & $-0,627$ \\
\hline $\begin{array}{l}\text { Centro de alfabetiza- } \\
\text { ción }\end{array}$ & $-0,426$ & $-0,483$ \\
\hline Primaria & $-0,132$ & $-0,200$ \\
\hline Secundaria & 0,219 & 0,133 \\
\hline Universitaria & 0,534 & 0,462 \\
\hline LCD & & \\
\hline Ninguno & $-0,041$ & $-0,191$ \\
\hline 1 & 0,659 & 0,319 \\
\hline 2 & 0,970 & 0,630 \\
\hline 3 & 1,122 & 0,850 \\
\hline 4 & 1,197 & 1,044 \\
\hline 5 & 1,309 & 1,188 \\
\hline 6 & & 1,262 \\
\hline 7 & & 1,336 \\
\hline 8 & 0,162 & 1,461 \\
\hline Refrigeradoras & & $-0,505$ \\
\hline Ninguno & 0,063 & $-0,155$ \\
\hline 1 & 0,589 & 0,389 \\
\hline Laptops & 1,077 & 0,716 \\
\hline Ninguno & & 0,921 \\
\hline 1 & & \\
\hline 2 & & \\
\hline 3 & & \\
\hline
\end{tabular}




\begin{tabular}{|c|c|c|}
\hline 4 & 1,242 & 1,092 \\
\hline 5 & & 1,272 \\
\hline 6 & & 1,454 \\
\hline \multicolumn{3}{|l|}{ Lavadoras } \\
\hline Ninguno & $-0,173$ & $-0,259$ \\
\hline 1 & 0,458 & 0,349 \\
\hline \multicolumn{3}{|l|}{ Microondas } \\
\hline Ninguno & $-0,139$ & $-0,165$ \\
\hline 1 & 0,548 & 0,496 \\
\hline \multicolumn{3}{|l|}{ Número de Vehículos } \\
\hline Ninguno & $-0,116$ & $-0,132$ \\
\hline 1 & 0,429 & 0,411 \\
\hline 2 & 0,762 & 0,769 \\
\hline 3 & 0,964 & 1,002 \\
\hline 4 & 1,117 & 1,147 \\
\hline 5 & 1,289 & 1,307 \\
\hline \multicolumn{3}{|l|}{6} \\
\hline \multicolumn{3}{|l|}{ Eliminación de Excreta } \\
\hline No tiene & $-0,697$ & $-0,661$ \\
\hline Letrina & $-0,501$ & $-0,509$ \\
\hline Inodoro y pozo ciego & $-0,359$ & $-0,427$ \\
\hline Inodoro y pozo séptico & $-0,159$ & $-0,235$ \\
\hline Inodoro y alcantarillado & 0,240 & 0,180 \\
\hline
\end{tabular}

Fuente: ENEMDU 2011 y 2017. 


\section{Discusión}

Analizando las estimaciones del índice de riqueza ( Ver Figura A1) para las distintas bases se aprecia un valor de asimetría ligeramente negativo pero cercano a cero y un valor de curtosis positivo; esto implica que la técnica reveló una concentración de datos a la izquierda con sesgo hacia la derecha en 2011, distribución similar a lo obtenido por Amek et al. (2015). Sin embargo, debido a una gran proporción de hogares con activos similares, principalmente en la posesión de por lo menos un activo en el hogar, la distribución del indicador fue más normal en 2017.

Al considerar el índice de riqueza estandarizado 7 que se observa en la Figura 1, se registran resultados bastante asimétricos de acuerdo al área de ubicación del hogar, ya sea a nivel de todas las observaciones nacionales o segmentando por área urbana o rural. Así, por ejemplo, los hogares del área urbana presentan un valor promedio de 0,39, sin distinción del año y la base de datos de estudio. Por otro lado, el área rural muestra una ligera mejoría en el año 2017, sin embargo, es un valor muy por debajo del indicador nacional esto demuestra las fuertes diferencias territoriales presentes en el Ecuador (Mendieta y Pontarollo, 2015; Orellana et al., 2016). Por lo tanto, un índice que no tome en cuenta las características propias del territorio podría sesgar los resultados ${ }^{8}$.

En este sentido, se puede observar como un dato de interés que el sector rural presenta un índice inferior respecto al sector urbano y en referencia a todas las observaciones nacionales, resaltando así las fuertes disparidades en estas dos áreas.

$7 \quad$ Estandarizado equivale a aproximar un valor entre 0 y 1 . En adelante el análisis se realiza considerando esta estimación.

8 En referencia a la ENIGHUR, los resultados no difieren significativamente respecto a la ENEMDU 2011 (Ver figura A2). 
Figura 1. Índice de Riqueza Estandarizado. A nivel nacional y por área de ubicación

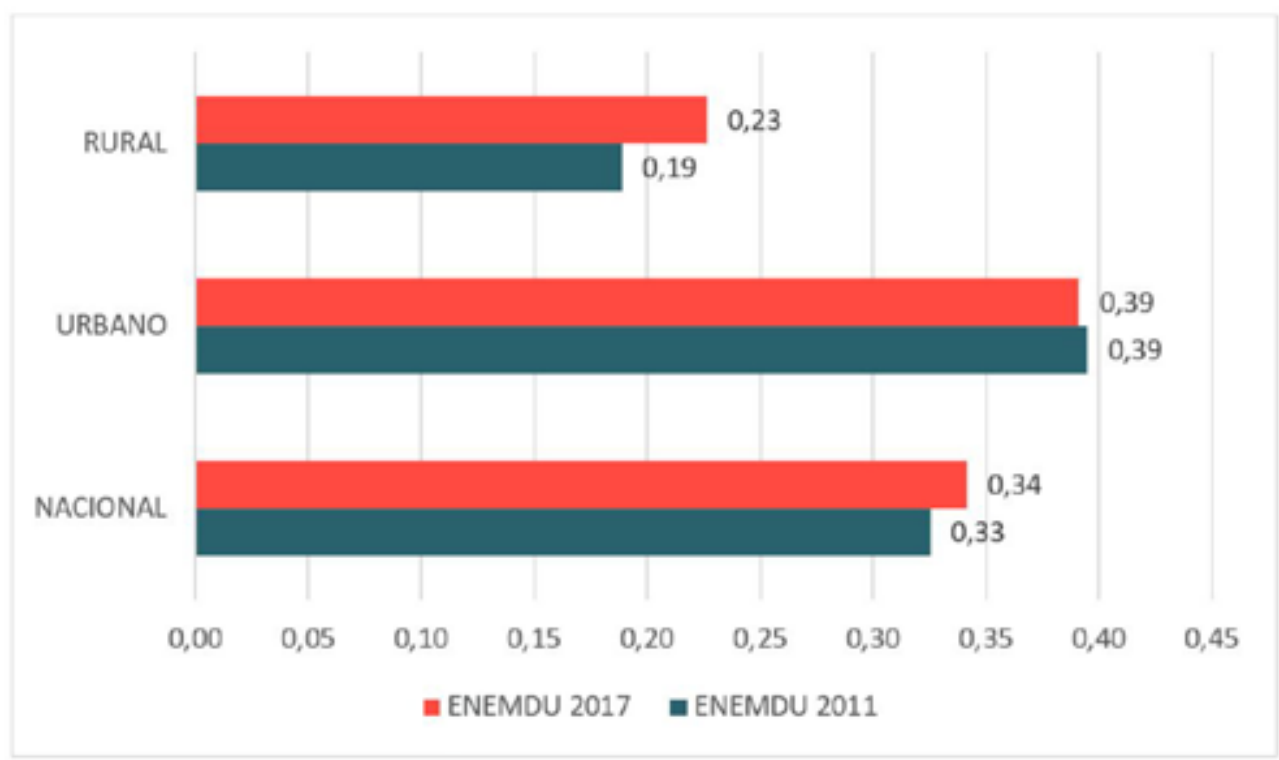

Fuente: ENEMDU, 2011 y 2017.

Al correlacionar este índice de riqueza con el ingreso per cápita revelado por los hogares dentro del período de análisis, se reporta una correlación positiva y significativa cercana a 0.40 para todos los años de estudio (ver tabla A6). Sin embargo, esta correlación no es homogénea a nivel de área de localización del hogar, dado que el índice de riqueza tiene una menor correlación para el año 2017 y para el sector rural, resaltando las características propias que tienen los territorios en Ecuador. Es decir, esta menor correlación implica que el índice de riqueza propuesto, mide otras dimensiones que el ingreso no lo hace, por lo que éste es un aporte para completar las medidas de bienestar (McKenzie, 2005). 
Figura 2. Índice de Gini del índice de riqueza estandarizado, a nivel Nacional y por Área

a) ENEMDU 2011

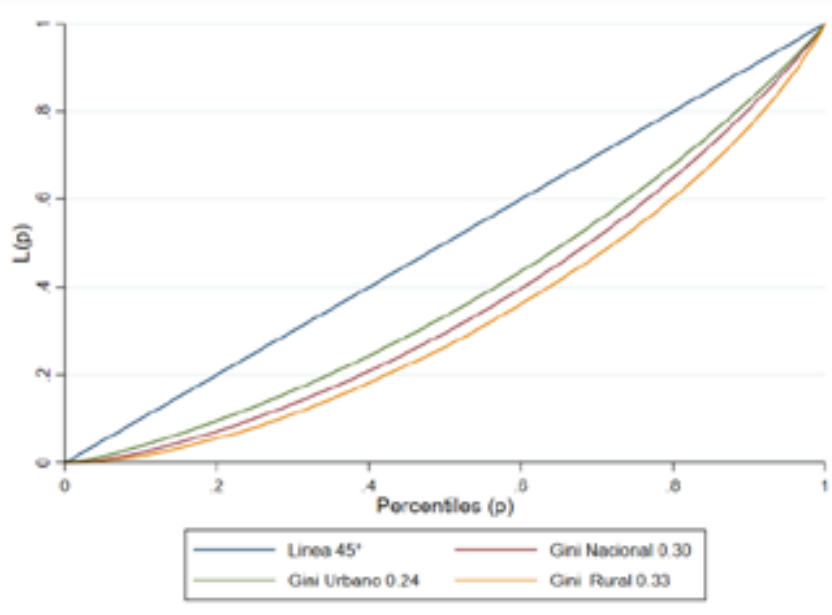

b) ENEMDU 2017

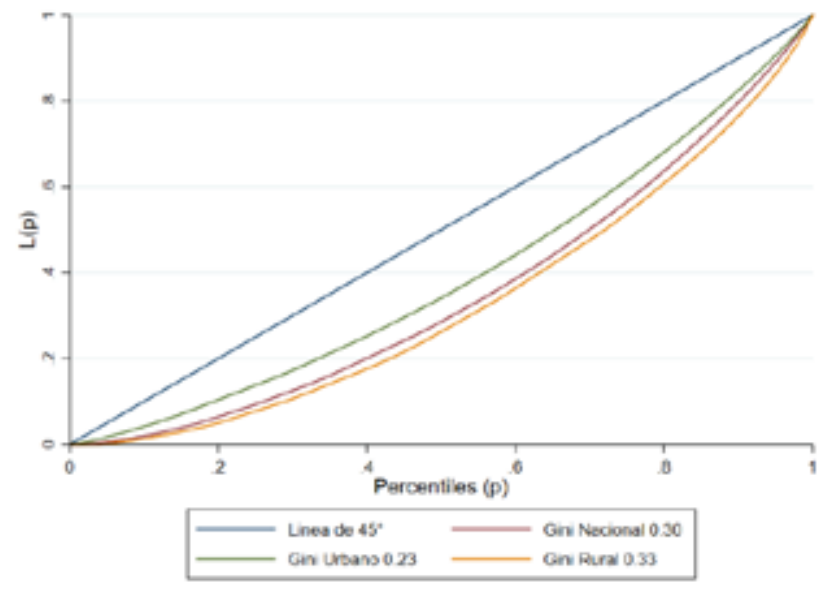


Asimismo, este indicador evidencia un índice de Gini mucho menor que otras medidas tradicionales de bienestar como el ingreso", pues, su coeficiente es de 0,30 y permanece invariante en los años, como se observa en la Figura 2. No obstante, estos valores difieren significativamente entre áreas de estudio, dado que para el sector rural se reporta un índice de desigualdad 10 puntos mayor al urbano y 3 puntos al nacional. Además, las brechas urbano-rural no han disminuido, dato que evidencia la persistencia en estas disparidades (Cielo, 2017)no solo en la variable ingreso, sino también en la riqueza (posesión de activos).

Es importante observar que la desigualdad en la tenencia de activos prácticamente se mantiene entre el periodo de análisis, especialmente, para el quintil más pobre y más rico, aunque, es notorio el mejoramiento de la posesión de activos del hogar en 2017, explicado fundamentalmente por el mayor poder adquisitivo de los hogares. Sin embargo, este incremento de los ingresos, no permite mejorar en una misma magnitud determinadas variables socioeconómicas como el acceso a la educación. En este sentido, se evidencia un rezago en el logro de servicios básicos, variable que no solo depende del hogar sino también de los Gobiernos Municipales encargados en dotar de dichos servicios a la población.

Con el objetivo de respaldar los resultados obtenidos y darles una mayor robustez, se calcula el índice de riqueza con la metodología de análisis por componentes principales compuestos, que a diferencia del policórico, no permite obtener una ponderación individual de las variables determinantes del indicador de riqueza propuesto. La metodología de componentes principales se basa específicamente en un valor simplicado, construido mediante las relaciones que se presentan entre $p$ variables correlacionadas, expresadas mediante combinaciones lineales que se van construyendo según el orden de importancia en cuanto a la variabilidad total que se recogen de la muestra (Uriel y Aldás, 2005).

En la Tabla 3 se observa el valor del indicador de riqueza comparando dos metodologías (PCA policórico y PCA compuesto) según las observaciones totales y por quintiles ${ }^{10}$. En 2011, se evidencia un valor

9 El Gini por ingresos para Ecuador en 2011 fue de 45,9; mientras que, en 2017 fue de 44,7 (Banco Mundial, 2017).

10 Los quintiles fueron estimados según la distribución de los indicadores de riqueza construidos. 
mayor del indicador considerando las correlaciones policóricas en referencia al indicador por componentes principales. Por lo que se evidencia una mejor composición de la posesión de bienes de los hogares (Balen et al., 2010). Además, en 2017 se observa que para las dos metodologías aplicadas, incrementa el indicador de riqueza, especialmente, estimando mediante componentes principales, respaldando una consistencia interna y solidez en ambos métodos, en particular para los hogares de mayor nivel de posesión de activos (quintil 5).

Tabla 3. Indicador de riqueza por metodologías policórica y PCA compuesto

\begin{tabular}{|c|c|c|c|c|}
\hline & \multicolumn{2}{|c|}{ ENEMDU 2011 } & \multicolumn{2}{c|}{ ENEMDU 2017} \\
\hline Quintil & $\begin{array}{c}\text { Indicador } \\
\text { riqueza PCA } \\
\text { policórico }\end{array}$ & $\begin{array}{c}\text { Indicador } \\
\text { riqueza PCA } \\
\text { compuesto }\end{array}$ & $\begin{array}{c}\text { Indicador } \\
\text { riqueza PCA } \\
\text { policórico }\end{array}$ & $\begin{array}{c}\text { Indicador } \\
\text { riqueza PCA } \\
\text { compuesto }\end{array}$ \\
\hline 1 & 0,193 & 0,125 & 0,217 & 0,166 \\
\hline 2 & 0,259 & 0,149 & 0,287 & 0,191 \\
\hline 3 & 0,316 & 0,172 & 0,334 & 0,213 \\
\hline 4 & 0,379 & 0,201 & 0,392 & 0,245 \\
\hline 5 & 0,478 & 0,256 & 0,481 & 0,300 \\
\hline Total & $\mathbf{0 , 3 2 1}$ & $\mathbf{0 , 1 8 2}$ & $\mathbf{0 , 3 4 2}$ & $\mathbf{0 , 2 2 1}$ \\
\hline
\end{tabular}

Fuente: ENEMDU 2011 y 2017.

Además se observa una mayor dispersión entre quintiles del indicador considerando PCA policórico, pues, en 2011, existió una diferencia del indicador entre el quintil 5 y 1 de 2,4 veces en comparación del indicador por componentes principales, cuya brecha fue de 2 veces. Para 2017, disminuyeron ligeramente estas diferencias entre los distintos segmentos de la distribución, siendo validado este comportamiento por la Encuesta de Ingresos y Gastos (Ver Tabla A7). 
En la Tabla 4 se observa a los hogares según su clasificación por quintiles, tanto por el indicador de riqueza por PCA policórico y por el de componentes principales compuestos. Es decir, nos indica por ejemplo, cuántos hogares que pertenecen al quintil 1, por el método de PCA policórico pertenecen en el mismo quintil por método de componentes principales compuesto. En este sentido, al observar la diagonal de la matriz, los valores son relativamente altos, evidenciando consistencia de las metodologías empleadas dentro del período de análisis ${ }^{11}$. Por ejemplo, se observa que en 2011, del total de hogares que pertenecían al quintil 1 según el PCA policórico, el 96\% pertenecen al quintil 1 según la metodología por componentes principales compuestos. Mientras que, en 2017, del total de hogares que pertenecen al quintil más rico según el PCA policórico, el $6 \%$ y $94 \%$ pertenecen al quintil 4 y 5 respectivamente según componentes principales.

Tabla 4: Porcentaje de personas según clasificación de quintiles por PCA policórico y PCA compuesto

\begin{tabular}{|c|c|c|c|c|c|c|c|c|c|c|}
\hline & \multicolumn{9}{|c|}{ ENEMDU 2011 } & \multicolumn{7}{|c|}{ ENEMDU 2017} \\
\hline & & \multicolumn{9}{|c|}{ PCA compuesto } \\
\hline $\begin{array}{c}\text { PCA } \\
\text { Policórico }\end{array}$ & $\mathbf{1}$ & $\mathbf{2}$ & $\mathbf{3}$ & $\mathbf{4}$ & $\mathbf{5}$ & $\mathbf{1}$ & $\mathbf{2}$ & $\mathbf{3}$ & $\mathbf{4}$ & $\mathbf{5}$ \\
\hline 1 & $\mathbf{9 6 \%}$ & $3 \%$ & $1 \%$ & $0 \%$ & $0 \%$ & $\mathbf{8 7} \%$ & $12 \%$ & $2 \%$ & $0 \%$ & $0 \%$ \\
\hline 2 & $3 \%$ & $\mathbf{8 2} \%$ & $14 \%$ & $0 \%$ & $0 \%$ & $3 \%$ & $\mathbf{5 1 \%}$ & $18 \%$ & $0 \%$ & $0 \%$ \\
\hline 3 & $0 \%$ & $0 \%$ & $\mathbf{8 7} \%$ & $13 \%$ & $0 \%$ & $0 \%$ & $17 \%$ & $\mathbf{6 8 \%}$ & $14 \%$ & $0 \%$ \\
\hline 4 & $0 \%$ & $0 \%$ & $8 \%$ & $\mathbf{8 0} \%$ & $12 \%$ & $0 \%$ & $0 \%$ & $17 \%$ & $\mathbf{7 6 \%}$ & $7 \%$ \\
\hline 5 & $0 \%$ & $0 \%$ & $0 \%$ & $0 \%$ & $\mathbf{1 0 0} \%$ & $0 \%$ & $0 \%$ & $0 \%$ & $6 \%$ & $\mathbf{9 4} \%$ \\
\hline
\end{tabular}

Fuente: ENEMDU 2011 y 2017.

$11 \quad$ Empleando la Encuesta Nacional de Ingresos y Gastos (2011), se evidencia menores valores en la diagonal principal respecto a la Encuesta de Empleo y Desempleo, por lo que se registra una mayor validación de las metodologías en los quintiles 1, 4 y 5 tal como lo menciona Bayen et al. (2010). 
En cuanto a la desigualdad medida por el índice de Gini, se registra un menor nivel de disparidad en la posesión de activos para los hogares ecuatorianos con el método de componentes principales para 2011 como para 2017 en comparación al método de componentes policóricos en casi 5 puntos (Ver Figura A3), resultado que es confirmado por la Encuesta Nacional de Ingresos y Gastos del Ecuador. Es importante destacar que el nivel de desigualdad también ha disminuido entre el periodo de análisis mediante la aplicación de las dos metodologías; sin embargo, tal como menciona Fan et al. (2003), estas diferencias pueden ser estructurales debido, principalmente, a la urbanización, modernización y accesibilidad de bienes y servicios, que a la riqueza en sí, y más en el caso de Ecuador, en donde como se evidenció en el presente estudio, existen amplias asimetrías territoriales.

En la Tabla 5 se observa la clasificación de los hogares por quintiles según el índice policórico de riqueza propuesto y el ingreso percápita a nivel nacional, variable que es obtenida directamente de la Encuesta Nacional de Empleo y Desempleo de Ecuador para 2011 y 2017. Se estima que existe una baja correspondencia entre quintiles empleando las dos variables mencionadas, pues, del total de los hogares que pertenecen a los quintiles 2,3 y 4 según la metodología del policórico, apenas en un $27 \%$ en promedio pertenecen a los mismos quintiles según el ingreso percápita de los hogares. Para el quintil 1 y 5 este porcentaje mejora al $42 \%$ y $53 \%$ respectivamente, evidenciando que las unidades familiares son clasificadas de distinta manera según estos dos indicadores que representan el nivel de riqueza de la población, siendo más robusto en el quintil más bajo y alto de la distribución. En este sentido, se observa que el indicador de riqueza ubicada en una mejor posición de bienestar a los hogares ecuatorianos en comparación al nivel de ingresos, dado que, por ejemplo en 2011, del total de hogares que pertenecen al quintil 3 según la metodología poliórica, el 66\% se encuentra en el quintil 1,2 o 3 según el nivel de ingresos percápita ó del total de hogares que pertenecen al quintil 4 según el indicador de riqueza policórico, el 75\% se ubica en quintiles inferiores considerando el nivel de ingresos percápita. Este comportamiento se mantiene relativamente constante entre el periodo de estudio. 
Tabla 5: Porcentaje de personas según clasificación de quintiles por PCA policórico y por ingresos percápita. A nivel nacional

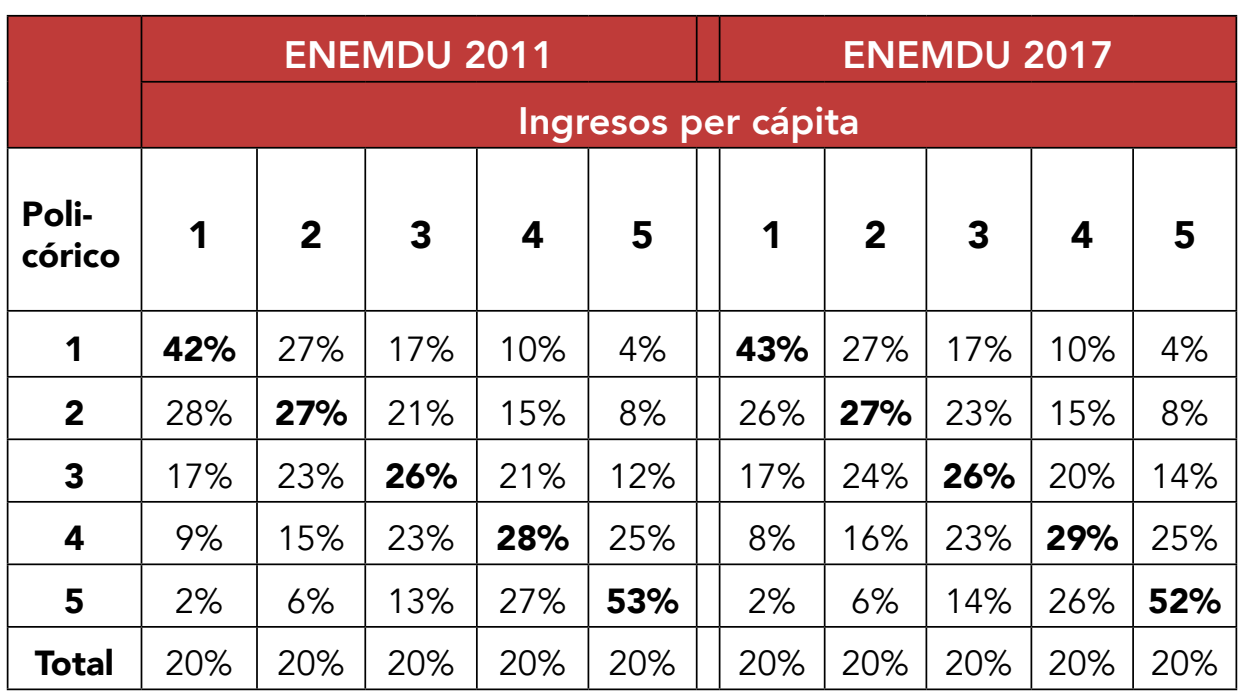

Fuente: ENEMDU 2011 y 2017.

En la Tabla A9 se detalla la clasificación de los hogares por quintiles, según el índice policórico de riqueza y el ingreso percápita por área urbana y rural. El comportamiento y relación débil es bastante similar a las observaciones nacionales, evidenciando una mayor comparabilidad en los quintiles 1 y 5 ; mientras que, para el área rural, la correspondencia entre quintiles es menor, lo que se estima que posiblemente este indicador sea más representativo en el área urbana que la rural tal como lo menciona Balen et al. (2010).

En la Tabla 6 se calcula los indicadores de desigualdad de Gini, desviación estándar y límites superiores e inferiores del indicador de riqueza según la metodología policórica y por ingreso percápita. Se evidencia que según el nivel de ingreso de los hogares la desigualdad es mucho más asentada en comparación a la medición de riqueza por componentes principales policórico, con una diferencia de casi 0.2 puntos. Por otro lado, se registra una mayor desviación y disparidad entre límites superiores e inferiores cuando se emplea el nivel de ingresos percápita de los hogares, respaldando que el indicador de riqueza construido 
representa de mejor manera la distribución del nivel de bienestar de la población.

Tabla 6: Nivel de desigualdad y descriptivos básicos entre indicador de riqueza policórico e ingreso percápita

Año Índice Gini Desv. Std $\begin{gathered}\text { Lím. } \\ \text { Inferior }\end{gathered}$ Superior

\section{ENEMDU}

\section{1}

\begin{tabular}{lllll} 
Policórico & 0.3013 & 0.0020 & 0.2974 & 0.3052 \\
\hline $\begin{array}{l}\text { Ingreso Per } \\
\text { Cápita }\end{array}$ & 0.4868 & 0.0043 & 0.4783 & 0.4952
\end{tabular}

ENEMDU

2017

\begin{tabular}{lllll}
\hline Policórico & 0.2845 & 0.0017 & 0.2812 & 0.2877 \\
\hline $\begin{array}{l}\text { Ingreso Per } \\
\text { Cápita }\end{array}$ & 0.4765 & 0.0043 & 0.4681 & 0.4848 \\
\hline
\end{tabular}

Fuente: ENEMDU 2011 y 2017.

Finalmente, desde la figura A2 a la A4 se representa el nivel de desigualdad estimado según el indice de riqueza por componentes principales policórico y el ingreso percápita, respaldando los hallazgos encontrados anteriormente, que al medir el nivel de desigualdad según los ingresos monetarios es mayor en comparación al nivel de riqueza multidimensional según la metodología policórica tanto a nivel nacional como por área de residencia, registrando que la diferencia en el nivel de desigualdad medida según el índice policórico y por el nivel de ingresos en el área urbana es mayor en relación a la rural. Entre los periodos de estudio no existe un cambio significativo en la desigualdad de posesión de activos y de ingresos de los hogares, reflejando la condición estructural sobre la carencia de bienes y rezago en el bienestar de la población ecuatoriana. 


\section{Conclusiones}

Este estudio contribuye a la estimación de un indicador de riqueza, como medida alternativa a los indicadores tradicionales del ingreso o consumo, que permitan determinar y analizar el nivel de bienestar de 2011 y 2017 en Ecuador. Para ello, se aplicó un nuevo método difundido en la literatura que permite representar la riqueza de un hogar mediante la estimación de pesos representativos respecto a la tenencia de los activos en los hogares aplicando el método de análisis de componentes principales (ACP) policórico.

Si bien, el presente estudio se basa en medidas indirectas de riqueza o consumo para estimar un índice de bienestar familiar, es importante destacar que estos indicadores proxy están sujetos a errores de medición y siguen siendo medidas imperfectas del bienestar socioeconómico; además, puede verse afectado por el número de indicadores, pero también, de la naturaleza de las variables particulares incluidas en el índice.

Sin embargo, una de las principales ventajas del indicador propuesto frente a otros indicadores es que esta nueva metodología permite condensar la información de algunas variables considerando sus categorías tanto ordinales como numéricas; además, permite representar de mejor manera el bienestar del hogar, permitiendo comparaciones intertemporales. Del mismo modo, la construcción de índices basados en el ingreso, en el consumo o por componentes principales simples, ha sido criticada por ser subjetiva y no estandarizada (Lindelow, 2006). 
El indicador de riqueza propuesto está conformado por tres componentes básicamente: caracterización del hogar, posesión de activos domésticos y calidad de servicios básicos; sin embargo, debido a la disponibilidad de información y compatibilidad de los datos según el periodo de análisis, se utilizó un número limitado de variables que, en función de la literatura revisada, resulta útil por el carácter multidisciplinario en la aplicación de las encuestas de salud, educación y consumo de los hogares, para demostrar las asociaciones de la pobreza y el acceso a los servicios sociales y económicos.

En general, los resultados obtenidos evidencian que existe una significativa correlación entre las dos medidas de bienestar como son los ingresos y el índice de riqueza de los hogares propuesto; esto se registra a nivel nacional, por cada uno de los quintiles de la distribución de ingresos (ver tabla A2) y por área de ubicación del hogar. No obstante, se correlaciona con mayor determinación en los quintiles superiores de la distribución y en el sector urbano. Estos hallazgos, indican el relieve en las diferencias estructurales de la riqueza, muy probablemente como resultado de la urbanización y modernización localizadas (Balen et al. 2010). Además, resulta importante observar que en los hogares más ricos se estima un índice de riqueza mucho mayor que los hogares más pobres, manteniéndose prácticamente dicha disparidad entre el periodo de tiempo analizado. Si bien esta medida muestra una consistencia comparando con ingresos tradicionales o por metodologías distintas como por componentes principales compuestos captura, de manera significativa, el bienestar del hogar, apoyando así su papel como medida complementaria de la situación socioeconómica de los hogares.

Por otro lado, los resultados también evidencian un aumento general en el número de hogares que adquieren activos a lo largo del tiempo; entre 2011 y 2017, se presenta un incremento del índice sobre todo en los hogares más pobres, por lo que refleja una mejora en el bienestar de dichos hogares, resultados similares a los obtenidos por Amek et al. (2015) y de Moser y Felton (2007). Al analizar la ubicación de los hogares según quintiles de ingreso y del indicador de riqueza, se mantiene una importante tendencia en los quintiles 1 y 5 específicamente; este comportamiento es más evidente al momento de contrastar la categorización por quintiles entre el indicador estimado con PCA policórico y PCA compuesto. Sin embargo, a diferencia de la medición 
de bienestar por medio de los ingresos o gastos, que pueden ser relativamente volátiles. El índice de riqueza construido es relativamente lento su cambio, debido a su composición, evidenciando ser una medida más exacta del nivel estructural de la condición socioeconómica de los hogares.

En cuanto a la asignación de pesos a los distintos bienes del hogar, se destaca una alta ponderación a la posesión de bienes como vehículos, laptops y cobertura de servicios básicos. Por otro lado, la posesión de lavadoras, microondas, refrigeradoras e instrucción del jefe del hogar obtienen un puntaje mucho menor, debido al consumo o la caracterización común que tienen estos bienes en los hogares. Ante ello, es importante fortalecer la adquisición de bienes durables en los hogares más pobres y estimular que su gasto sea destinado no solo en bienes privados, sino fortalecer el acceso a servicios básicos como componente de inversión y mejora del desarrollo económico de los territorios (Booysen et al. 2008).

El indicador de riqueza propuesto se explicó en una mayor proporción de datos en el entorno urbano que en el rural, lo que puede reforzar la preocupación de que un índice basado en activos sea más "apropiado" para medir la riqueza en las zonas urbanas en comparación con las zonas rurales. Para aumentar estos porcentajes, se pueden utilizar otras herramientas de análisis de datos como el modelo probit jerárquico ordenado modificado (Tandon et al., 2001) y el Análisis de Correspondencia Múltiple (MCA, por sus siglas en inglés) (Howe et al. 2009) para ponderar los indicadores y deben explorarse más en estudios posteriores.

Considerando la metodología aplicada, se ha contrastado los valores estimados por dos metodologías diferentes, PCA policórico y por PCA compuesto, además de obtener los niveles de desigualdad, según Gini, en donde se evidencia un valor mayor por correlaciones policóricas, sin mayor variación entre el periodo de estudio. Al comparar los quintiles por nivel de ingresos percápita y el indicador de riqueza policórico existe una importante divergencia en la clasificación, pues, de todos los hogares apenas el $26 \%$ de los quintiles 2,3 y 4, según la metodología policórica, pertenecen a estos mismos quintiles cuando se considera el ingreso de los hogares; además, se estima una mayor desigualdad y desviación en la distribución cuando se utiliza el ingreso percápita. También, se 
evidencia una importante conclusión, pues, el nivel de bienestar medida por los ingresos de los hogares ubica en una peor posición a los hogares, especialmente, a los quintiles 2,3 y 4 . En este contexto, se ha logrado tener una primera aproximación para el caso ecuatoriano: es necesario fortalecer una técnica que permita seleccionar variables que se adapten de mejor manera a la construcción de un indicador socioeconómico.

Si bien, está más allá del alcance de este documento explorar exhaustivamente los factores detrás de las disparidades, se sugiere una mayor investigación sobre las complejas interacciones entre estos y otros activos como el capital humano, acceso a servicios públicos y activos de larga duración (González et al., 2010). Esto permitiría establecer los determinantes de las diferencias observadas entre las medidas directas e indirectas de la riqueza, en donde se permita entender que la mejora de las condiciones de vida y la disminución de las brechas de desigualdad son importantes para la estabilidad sociopolítica nacional y regional. En este sentido, se ha evidenciado que cerrar la brecha de las zonas rurales a las urbanas es actualmente una de las principales prioridades que debería emprender las autoridades públicas de manera descentralizada y vinculada a la adquisición de bienes y acceso a servicios que conduzcan a un incremento del nivel socioeconómico y bienestar en los hogares ecuatorianos. 


\section{Referencias}

Abeyasekera, S. (2005). Chapter XVIII Multivariate methods for index construction. Reading (UK): University of Reading. hlm, 377-378

Alkire, S., y Foster, J. (2011). Counting and multidimensional poverty measurement. Journal of Public Economics, 95(7-8), 476-487.

Alkire, S. (2013). La Metodología Alkire y Foster. Ponencia presentada en Intensive Spanish-language Training Course.

Amek, N., Vounatsou, P., Obonyo, B., Hamel, M., Odhiambo, F., Slutsker, L., y Laserson, K. (2015). Using health and demographic surveillance system (HDSS) data to analyze geographical distribution of socio-economic status; an experience from KEMRI/CDC HDSS. Acta Tropica, 144, 24-30. https://doi.org/10.1016/j.actatropica.2015.01.006

Anghel, B., Basso, H. S., Bover Hidiroglu, O., Casado García, J. M., Hospido Quintana, L., Kataryniuk, I., ... \& Vozmediano Peraita, E. (2018). La desigualdad de la renta, el consumo y la riqueza en España. Documentos ocasionales/Banco de España, 1806.

Balen, J., McManus, D. , L, Y. , Zhao, Z., Yuan, L., Utzinger, J. (2010). Comparison of two approaches for measuring household wealth via an asset-based index in rural and peri-urban settings of Hunan province, China. Emerging Themes in Epidemiology, 7(1), 7. https://doi. org/10.1186/1742-7622-7-7

Banco Mundial (2021). Reporte de datos económicos. Disponible en: https://datos.bancomundial.org/indicador/NY.GDP.MKTP.KD.ZG?locations=EC

Bollen, K. , Glanville, J. y Stecklov, G. (2002). Economic status proxies in studies of fertility in developing countries: Does the measure matter? Population Studies, 56(1), 81-96. https://doi. org/10.1080/00324720213796

Booysen, F., Van der Berg, S., Burger, R., Maltitz, M. von, y Rand, G. du. (2008). Using an Asset Index to Assess Trends in Poverty in Seven Sub-Saharan African Countries. World Development, 36(6), 
1113-1130. https://econpapers.repec.org/article/eeewdevel/ v_3a36_3ay_3a2008_3ai_3a6_3ap_3a1113-1130.htm

Bourguignon, F., Chakravarty, S. R., 2003. The Measurement of Multidimensional Poverty. Journal of Economic Inequality. 1, 25-49.

Carter, M., y May, J. (2001). One Kind of Freedom: Poverty Dynamics in Post-apartheid South Africa. World Development, 29(12), 1987-2006. https://econpapers.repec.org/article/eeewdevel/v_3a29_3ay_3a2001_3 ai_3a12_3ap_3a1987-2006.htm

Cielo, C. (2017). Desigualdades y formas de gobierno en las articulaciones urbano-rurales. En Martínez Godoy, D. (Ed.). Relaciones y tensiones entre lo urbano y lo rural (Primera edición). Quito, Ecuador: Congope, Consorcio de Gobiernos Autónomos Provinciales del Ecuador : Ediciones Abya-Yala.

Deaton, A., y Zaidi, S. (2002). Guidelines for Constructing Consumption Aggregates for Welfare Analysis. World Bank Publications.

Fan SG, Zhang XB, Robinson S: Structural change and economic growth in China. Rev Dev Econ. 2003, 7 (3): 360-77. 10.1111/14679361.00196.

Fay, M., Leipziger, D., Wodon, Q., y Yepes, T. (2005). Achieving childhealth-related Millennium Development Goals: The role of infrastructure. World Development, 33(8), 1267-1284. https://doi. org/10.1016/j.worlddev.2005.03.001

Filmer, D., y Pritchett, L. H. (2001). Estimating Wealth Effects without Expenditure Data-or Tears: An Application to Educational Enrollments in States of India. Demography, 38(1), 115-132. https://doi. org/10.2307/3088292

Howe, L. , Hargreaves, J. , Gabrysch, S., y Huttly, S. (2009). Is the wealth index a proxy for consumption expenditure? A systematic review. Journal of Epidemiology and Community Health, 63(11), 871-877. https://doi.org/10.1136/jech.2009.088021

Instituto Nacional de Estadísticas y Censos en Ecuador (2011). Encuesta de Ingresos y Gastos de los Hogares en Ecuador, Disponible en: 
https://www.ecuadorencifras.gob.ec/encuesta-nacional-de-ingresos-y-gastos-de-los-hogares-urbanos-y-rurales/

Instituto de Investigaciones Socioeconómicas (2017). Ficha metodológica del coeficiente de Gini. Disponible en: http://www.iisec.ucb. edu.bo/assets_iisec/recurso/PobDes_Gini.pdf

Kennedy, G., Nantel, G., Brouwer, I. D., y Kok, F. J. (2006). Does living in an urban environment confer advantages for childhood nutritional status? Analysis of disparities in nutritional status by wealth and residence in Angola, Central African Republic and Senegal. Public Health Nutrition, 9(2), 187-193. https://doi.org/10.1079/ phn2005835

Kolenikov S, Angeles G (2004). (s. f.). The Use of Discrete Data in PCA: Theory, Simulations, and Applications to Socioeconomic Indices - MEASURE Evaluation [Publication]. https://www.measureevaluation.org/resources/publications/wp-04-85

Lambert, D. C. (1968). La repartición de los ingresos y las desigualdades sociales en América Latina. Revista Mexicana de Sociologia, 571592.

Lindelow M (2006). Sometimes more equal than others: how health inequalities depend on the choice of welfare indicator. Health Econ. 15 (3): 263-79.

Luby, S. , y Halder, A. (2008). Associations among handwashing indicators, wealth, and symptoms of childhood respiratory illness in urban Bangladesh: Handwashing indicators, wealth, and symptoms of childhood respiratory illness. Tropical Medicine \& International Health, 13(6), 835-844. https://doi.org/10.1111/j.13653156.2008.02074.x

McKenzie, D. (2005). Measuring Inequality with Asset Indicators. Journal of Population Economics, 18(2), 229-260. www.jstor.org/stable/20007957

Mendieta, R., y Pontarollo, N. (2015, diciembre 16). Cantonal Convergence in Ecuador: A Spatial Econometric Perspective [MPRA Paper]. https://mpra.ub.uni-muenchen.de/72285/ 
Montgomery, M. R., Gragnolati, M., Burke, K. A., \& Paredes, E. (2000). Measuring living standards with proxy variables. Demography, 37(2), 155-174.

Moser, C., y Felton, A. (2007). Intergenerational Asset Accumulation and Poverty Reduction in Guayaquil Ecuador (1978-2004). Reducing Global Poverty: The Case for Asset Accumulation. https:// www.research.manchester.ac.uk/portal/en/publications/intergenerational-asset-accumulation-and-poverty-reduction-in-guayaquil-ecuador-19782004(bdba582a-c4ab-4461-acd5-022cff2e82 7ff/export.html

Olsson, U. (1979). Maximum likelihood estimation of the polychoric correlation coefficient. Psychometrika, 44(4), 443-460. https://doi. org/10.1007/BF02296207

Onwujekwe, O., Hanson, K., \& Fox?Rushby, J. (2006). Some indicators of socio?leconomic status may not be reliable and use of indices with these data could worsen equity. Health economics, 15(6), 639644.

Orellana, M. , Szeles, M. , y Barrera, D. (2016). A Multilevel Analysis of the Returns to Education in Ecuador. The Multifaceted Impact of Human Capital. Scientific Annals of Economics and Business, 63(s1), 1-19. https://doi.org/10.1515/saeb-2016-0133

Paraje, G. (2008). Evolución de la desnutrición crónica infantil y su distribución socioeconómica en siete países de América Latina y el Caribe. CEPAL

Pearson, K. (1901). LIII. On lines and planes of closest fit to systems of points in space. The London, Edinburgh, and Dublin Philosophical Magazine and Journal of Science, 2(11), 559-572. https://doi. org/10.1080/14786440109462720

Rigdon, E. , y Ferguson, C. (1991). The Performance of the Polychoric Correlation Coefficient and Selected Fitting Functions in Confirmatory Factor Analysis with Ordinal Data. Journal of Marketing Research, 28(4), 491-497. https://doi.org/10.1177/002224379102800412 
Sahn, D. , y Stifel, D. (2003). Exploring Alternative Measures of Welfare in the Absence of Expenditure Data. Review of Income and Wealth, 49(4), 463-489. https://doi.org/10.1111/j.00346586.2003.00100.x

Sahn, D. E., \& Stifel, D. C. (2000). Poverty comparisons over time and across countries in Africa. World development, 28(12), 2123-2155.

Sen, A. (1999). Development as Freedom, Oxford University Press, New York.

Schellenberg, J. , Victora, C. , Mushi, A., de Savigny, D., Schellenberg, D., Mshinda, H., ... Tanzania Integrated Management of Childhood Illness MCE Baseline Household Survey Study Group. (2003). Inequities among the very poor: Health care for children in rural southern Tanzania. Lancet (London, England), 361(9357), 561566. https://doi.org/10.1016/S0140-6736(03)12515-9

Sen, A. (1999). Commodities and Capabilities. https://ideas.repec.org/b/ oxp/obooks/9780195650389.html

Tandon A, Murray CJL, Salomon J, King G. (2001) Statistical models for enhancing cross-population comparability Global Programme on Evidence for Health Policy Discussion Paper No. 42.

Uriel, E y Aldás, J. (2005). Análisis multifactorial aplicado. Editorial Thomson- España. ISBN 8497323726

Ward, P. (2014). Measuring the Level and Inequality of Wealth: An Application to China. The Review of income and wealth, 60(4), 613635. https://doi.org/10.1111/roiw.12063 


\section{ANEXOS}

Tabla A1: Datos descriptivos de las variables estimadas a nivel Nacional, por quintiles de ingreso (\%) 


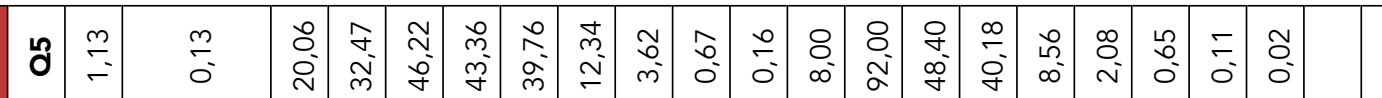

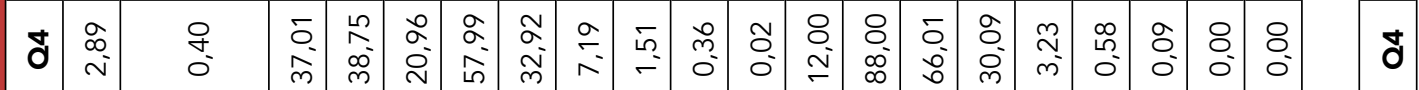

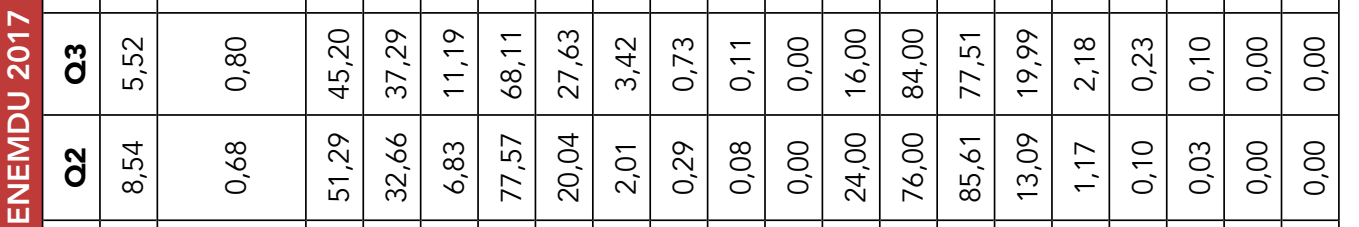

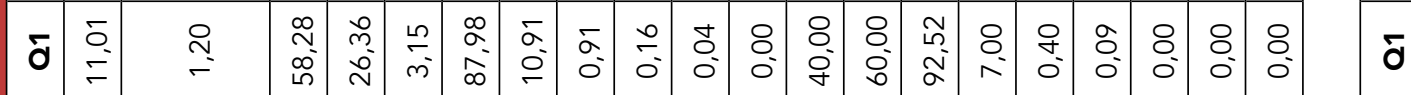

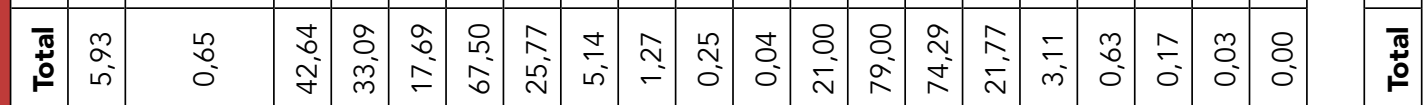

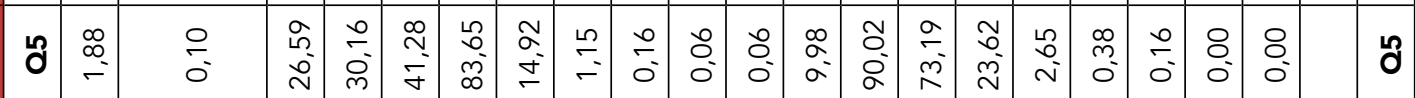

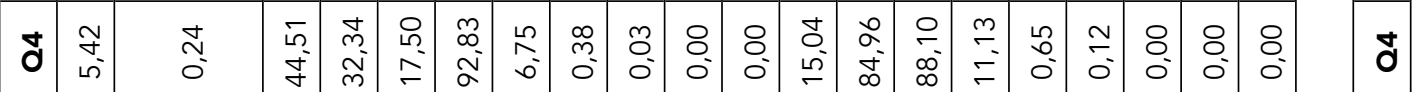

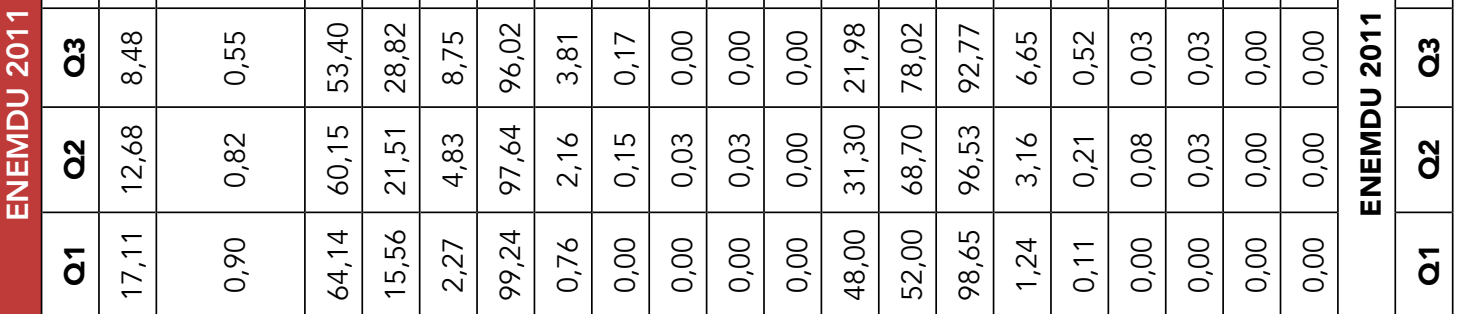

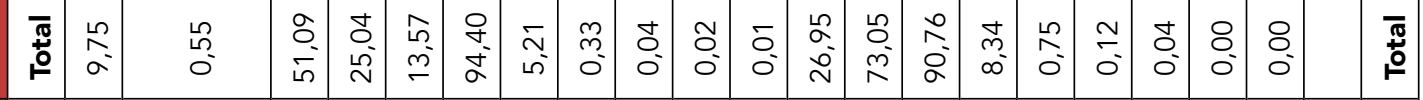

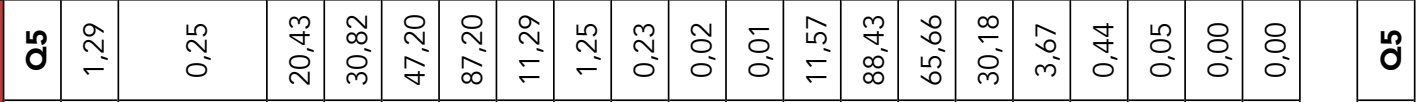

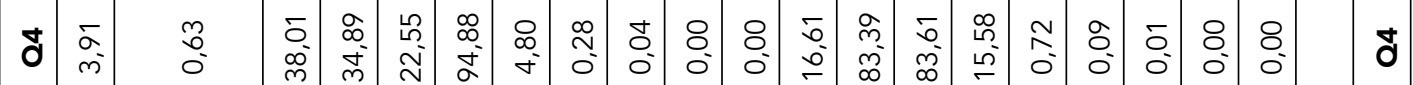

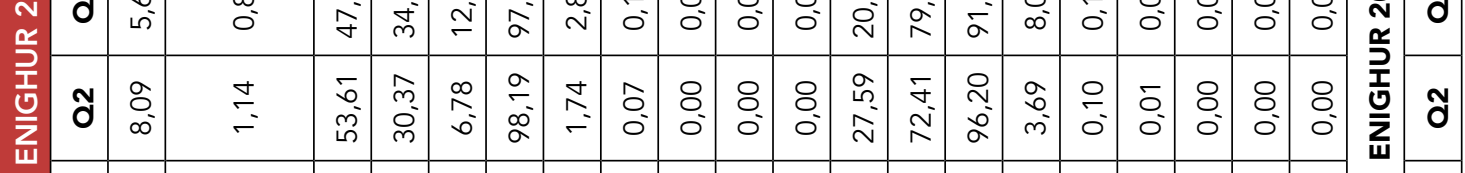

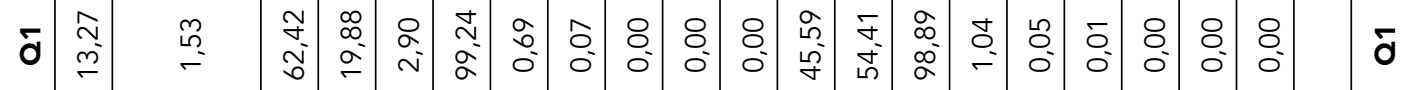

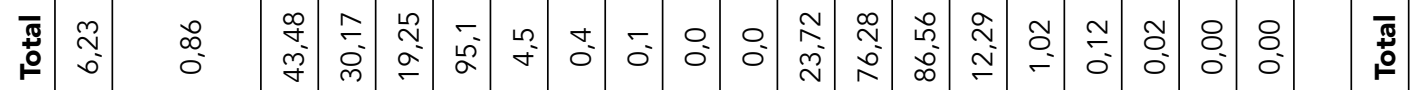

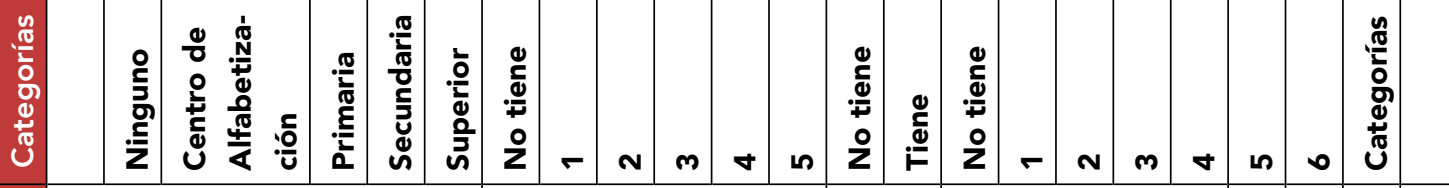

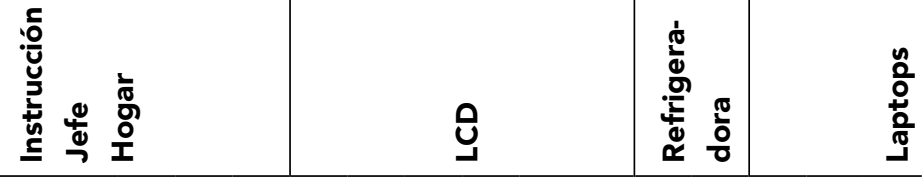




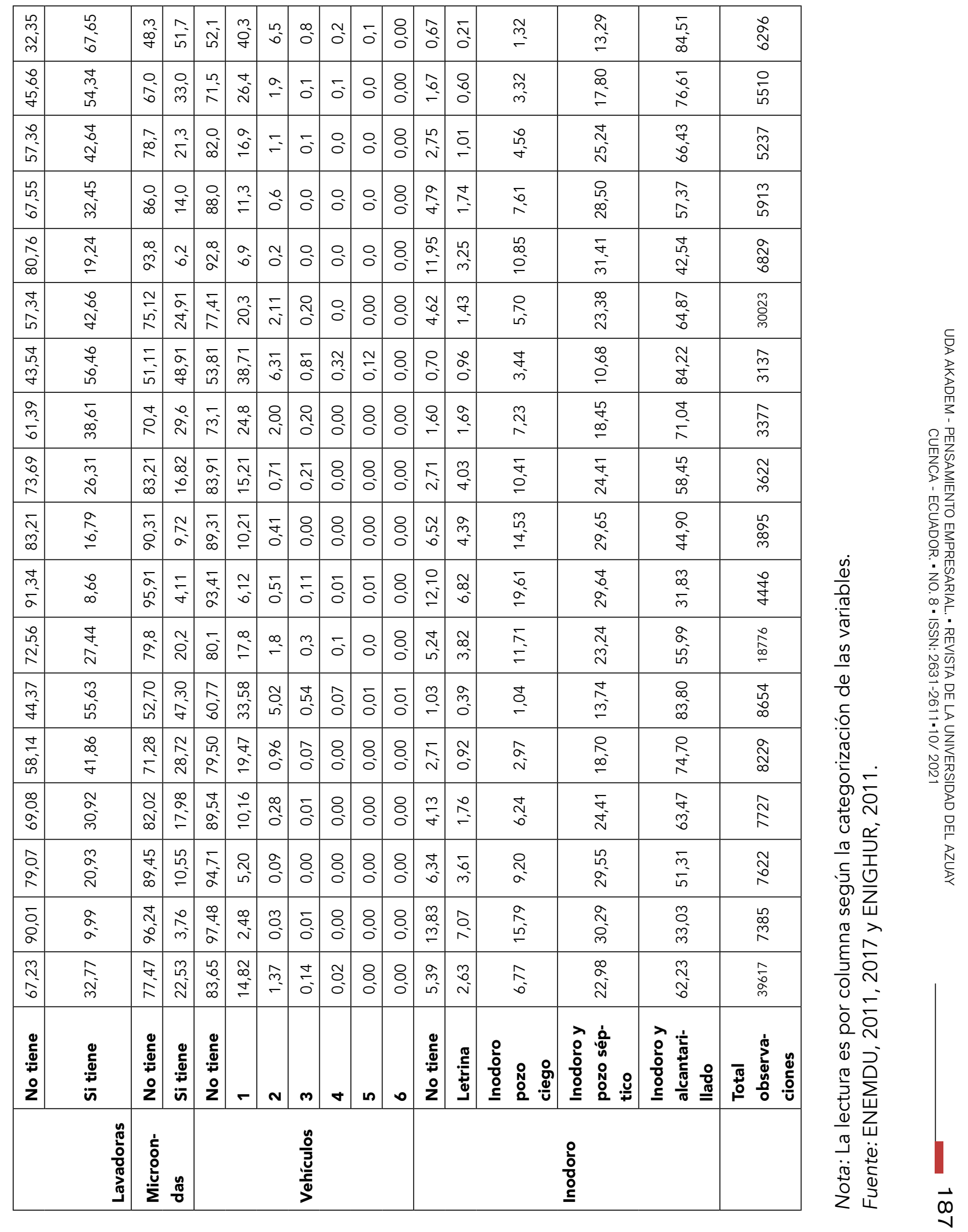




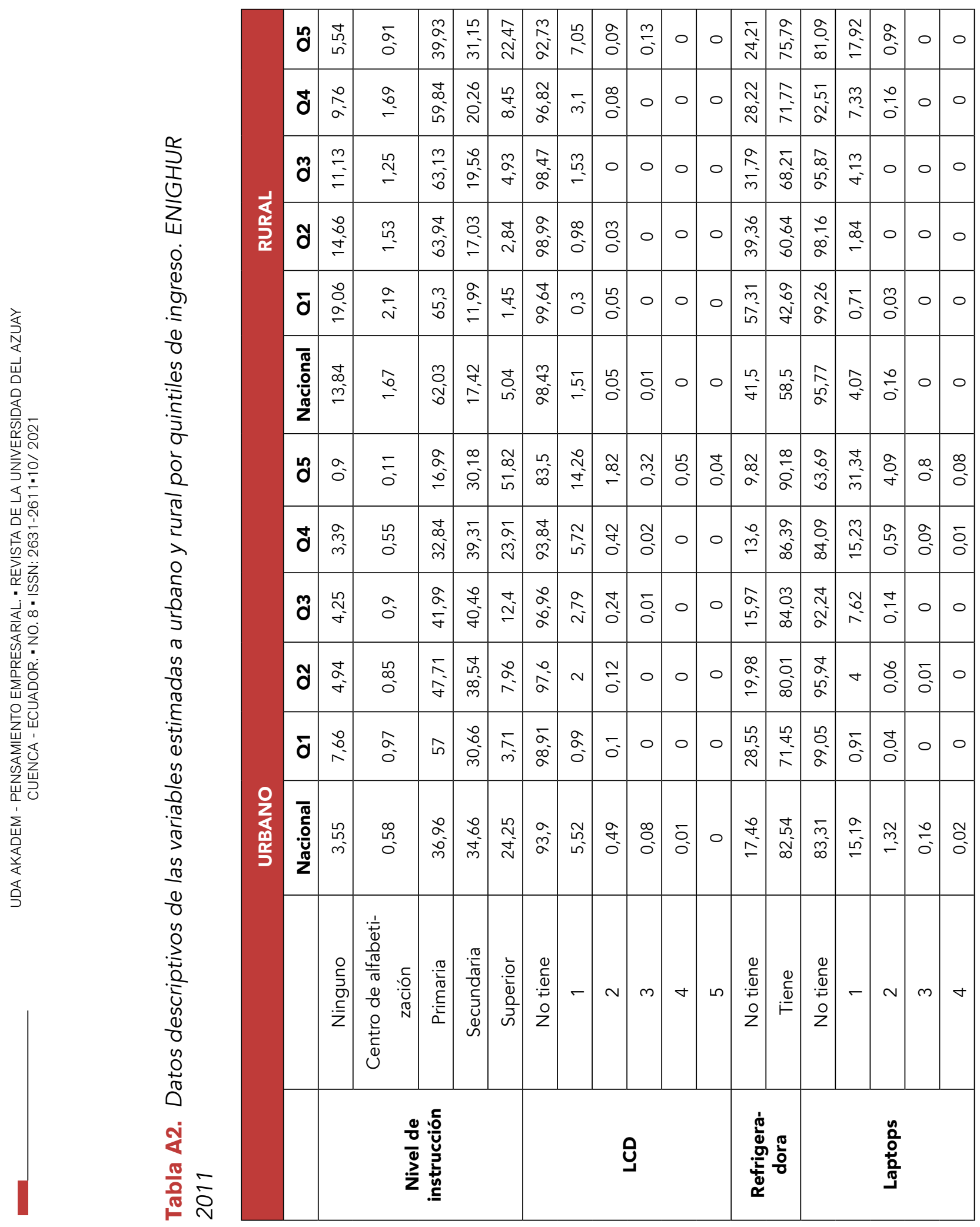




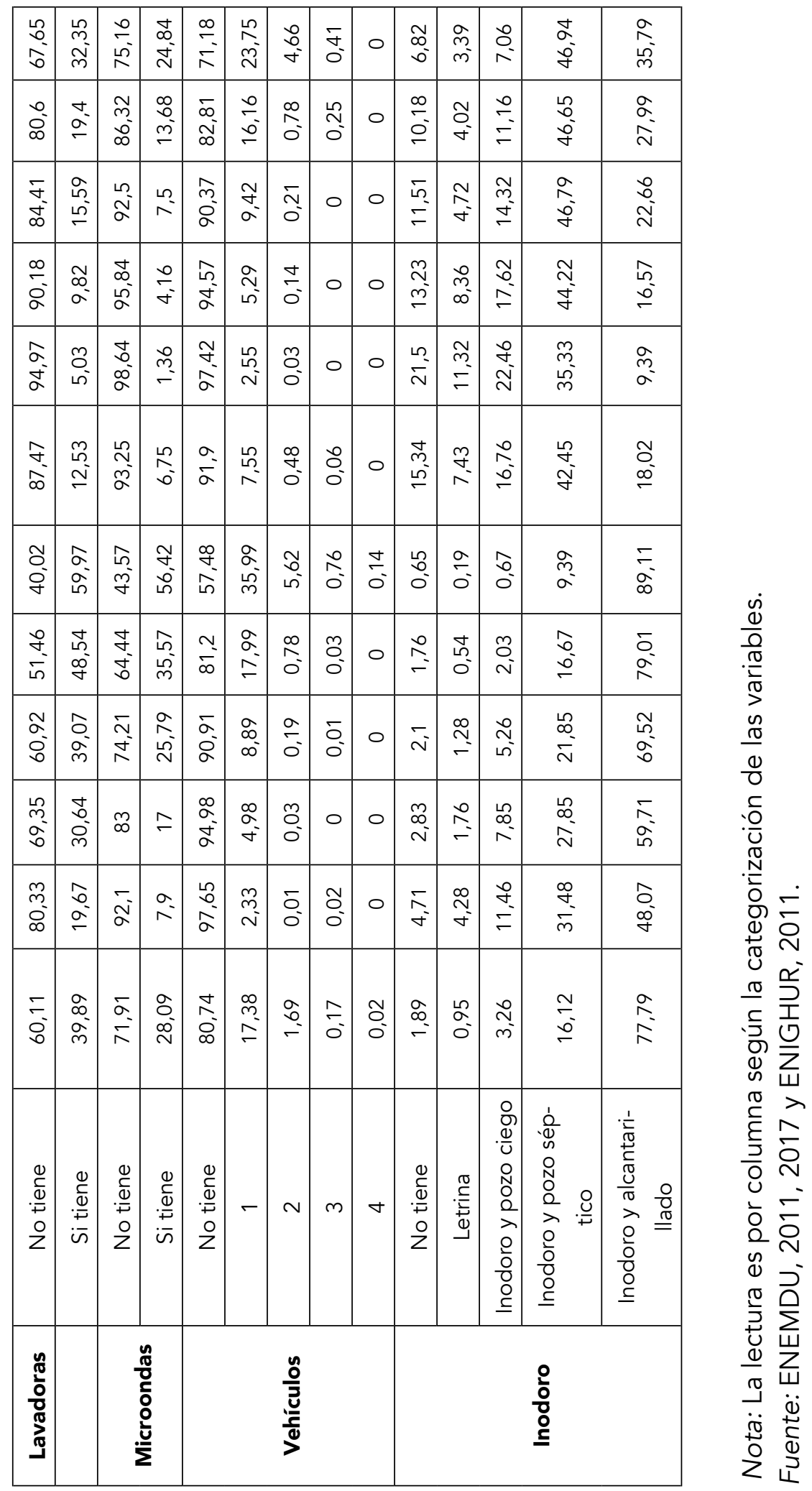




\begin{tabular}{|c|c|c|c|c|c|c|c|c|c|c|c|c|c|c|c|c|c|c|}
\hline O̊ & $\begin{array}{l}a \\
\hat{b}\end{array}$ & $\stackrel{\nabla}{\check{\sigma}}$ & 总 & $\begin{array}{l}\stackrel{2}{ } \\
\stackrel{\sim}{\sim}\end{array}$ & $\begin{array}{l}\stackrel{\infty}{\stackrel{\rho}{\rho}} \\
\stackrel{\rho}{\sim}\end{array}$ & $\begin{array}{l}\hat{\alpha} \\
\dot{\alpha}\end{array}$ & 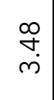 & $\begin{array}{l}\widetilde{O} \\
0\end{array}$ & 0 & 0 & 0 & $\begin{array}{l}\bar{N} \\
\stackrel{D}{\sim}\end{array}$ & 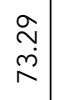 & $\begin{array}{c}\mathfrak{N} \\
\stackrel{\infty}{\infty}\end{array}$ & $\begin{array}{l}\stackrel{g}{o} \\
\bar{E}\end{array}$ & $\stackrel{\bar{m}}{-}$ & 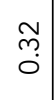 & 0 \\
\hline ठ & $\stackrel{\stackrel{\leftrightarrow}{\leftrightarrow}}{\stackrel{m}{r}}$ & $\begin{array}{l}\infty \\
0 \\
0 \\
0\end{array}$ & $\begin{array}{l}\text { N } \\
\stackrel{0}{0} \\
0\end{array}$ & 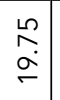 & $\begin{array}{l}\infty \\
\infty \\
\llcorner \\
\dot{0}\end{array}$ & $\begin{array}{l}+ \\
\stackrel{0}{\circ} \\
\curvearrowright\end{array}$ & $\underset{\dot{m}}{\stackrel{\nabla}{*}}$ & $\stackrel{\simeq}{\check{0}}$ & 0 & 0 & 0 & $\begin{array}{l}\infty \\
\infty \\
\infty \\
\sim \\
\sim\end{array}$ & $\underset{\leftarrow}{\stackrel{丶}{\Sigma}}$ & $\begin{array}{l}\hat{o} \\
\ddot{j} \\
\alpha\end{array}$ & $\begin{array}{l}\hat{\imath} \\
\stackrel{\hat{n}}{*}\end{array}$ & 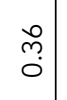 & 0 & 0 \\
\hline$\stackrel{\mathscr{g}}{ }$ & $\begin{array}{l}\stackrel{\llcorner}{m} \\
\stackrel{m}{\circ}\end{array}$ & $\underset{\leftarrow}{\check{\sigma}}$ & $\begin{array}{l}\sigma \\
\frac{\sigma}{b} \\
\dot{0}\end{array}$ & $\begin{array}{l}\stackrel{\infty}{\sim} \\
\stackrel{+}{\leftarrow}\end{array}$ & $\stackrel{\circ}{\circ}$ & $\begin{array}{l}n \\
0 \\
\infty \\
\alpha\end{array}$ & $\stackrel{\stackrel{n}{\longrightarrow}}{\rightarrow}$ & 0 & 0 & 0 & 0 & 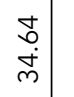 & $\begin{array}{l}\text { m. } \\
\text { Ln } \\
0.0\end{array}$ & $\begin{array}{l}\bar{\sigma} \\
2 \\
\alpha\end{array}$ & 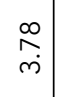 & $\stackrel{\mathfrak{N}}{\check{0}}$ & 0 & 0 \\
\hline ฮี & $\begin{array}{l}\llcorner \\
\infty \\
\infty \\
\stackrel{N}{N}\end{array}$ & $\stackrel{\stackrel{m}{m}}{\stackrel{2}{n}}$ & 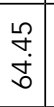 & $\begin{array}{l}m \\
\stackrel{0}{\sigma} \\
\dot{\leftarrow}\end{array}$ & $\stackrel{\curvearrowright}{\stackrel{N}{\sim}}$ & $\begin{array}{l}0 \\
\circ \\
\infty \\
\propto\end{array}$ & $\stackrel{\stackrel{m}{\longrightarrow}}{\longrightarrow}$ & 0 & 0 & 0 & 0 & $\begin{array}{l}\stackrel{\infty}{\sim} \\
\dot{f}\end{array}$ & $\begin{array}{l}\underset{N}{N} \\
\text { นn }\end{array}$ & $\begin{array}{l}\bar{o} \\
\infty \\
\alpha\end{array}$ & $\begin{array}{l}\infty \\
\stackrel{\infty}{\longrightarrow} \\
\leftarrow\end{array}$ & 0 & $\begin{array}{l}\stackrel{n}{\circ} \\
\stackrel{\circ}{\circ}\end{array}$ & 0 \\
\hline$\overline{0}$ & $\begin{array}{l}\bar{f} \\
\stackrel{\sim}{\sim}\end{array}$ & $\stackrel{\stackrel{\sim}{N}}{\stackrel{2}{n}}$ & $\begin{array}{l}\text { में } \\
\text { ம. }\end{array}$ & $\begin{array}{l}\infty \\
0 \\
\sigma\end{array}$ & $\begin{array}{l}\infty \\
\infty \\
0\end{array}$ & $\begin{array}{l}\stackrel{0}{2} \\
\frac{2}{\alpha}\end{array}$ & 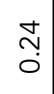 & 0 & 0 & 0 & 0 & $\stackrel{\substack{m \\
i n}}{i}$ & $\begin{array}{l}\underset{N}{0} \\
\underset{\mathcal{J}}{ }\end{array}$ & $\begin{array}{l}\stackrel{\infty}{N} \\
\stackrel{a}{\sigma}\end{array}$ & $\hat{o}$ & $\begin{array}{l}\tilde{O} \\
0 \\
0\end{array}$ & 0 & 0 \\
\hline $\begin{array}{l}\bar{\sigma} \\
\stackrel{0}{0} \\
\stackrel{0}{u} \\
\mathbb{Z} \\
Z\end{array}$ & $\begin{array}{l}\check{\sigma} \\
\stackrel{2}{\sigma}\end{array}$ & $\stackrel{\infty}{\leftarrow}$ & $\begin{array}{l}\hat{\infty} \\
\tilde{m} \\
\dot{0}\end{array}$ & $\begin{array}{l}\stackrel{⿱}{\infty} \\
\stackrel{ }{\longrightarrow}\end{array}$ & $\begin{array}{l}m \\
\stackrel{m}{v}\end{array}$ & $\begin{array}{l}\widetilde{0} \\
\infty \\
\infty\end{array}$ & $\stackrel{\sim}{\sim}$ & $\stackrel{\text { O̊. }}{\circ}$ & 0 & 0 & 0 & $\begin{array}{l}\stackrel{\vec{f}}{f} \\
\dot{\vec{J}}\end{array}$ & 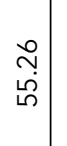 & $\begin{array}{l}\infty \\
0 \\
0 \\
\alpha\end{array}$ & $\begin{array}{c}\stackrel{N}{\infty} \\
\stackrel{\sim}{\sim}\end{array}$ & $\stackrel{0}{\circ}$ & $\stackrel{m}{0}$ & $\delta_{0}$ \\
\hline o & $\begin{array}{l}\hat{\infty} \\
0 \\
0\end{array}$ & 0 & 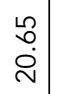 & $\begin{array}{l}\infty \\
0 \\
0 \\
\dot{m} \\
m\end{array}$ & $\begin{array}{l}\infty \\
\stackrel{\forall}{\forall}\end{array}$ & $\underset{\infty}{\underset{\infty}{\sim}}$ & $\begin{array}{l}\stackrel{m}{\sigma} \\
\stackrel{\sigma}{\sigma}\end{array}$ & $\stackrel{\nabla}{\leftarrow}$ & $\stackrel{\infty}{\leftarrow}$ & 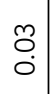 & $\begin{array}{l}m \\
O \\
0\end{array}$ & $\begin{array}{l}\hat{\imath} \\
\dot{\omega}\end{array}$ & $\begin{array}{l}\underset{N}{N} \\
\dot{\sigma}\end{array}$ & $\begin{array}{l}m \\
\text { O̦ } \\
\end{array}$ & 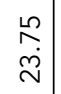 & $\stackrel{\infty}{\sim}$ & 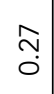 & $\stackrel{\llcorner}{\stackrel{\circ}{\circ}}$ \\
\hline 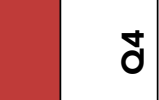 & $\stackrel{\sqrt[n]{n}}{i}$ & $\begin{array}{l}\tilde{O} \\
\text { Oे }\end{array}$ & $\begin{array}{l}\stackrel{+}{+} \\
\dot{m}\end{array}$ & 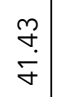 & $\stackrel{a}{\dot{\sim}}$ & $\begin{array}{l}\stackrel{m}{N} \\
\bar{a}\end{array}$ & $\underset{\infty}{\stackrel{亠}{\sigma}}$ & $\begin{array}{l}\stackrel{\infty}{0} \\
\stackrel{\leftrightarrow}{0}\end{array}$ & $\begin{array}{c}\tilde{O} \\
\text { Oे }\end{array}$ & 0 & 0 & $\stackrel{\overbrace{}}{\check{r}}$ & $\begin{array}{l}m \\
\infty \\
\\
\dot{\alpha}\end{array}$ & 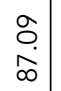 & 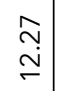 & 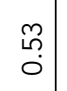 & $\bar{\sigma}$ & 0 \\
\hline ğ & $\stackrel{\vec{m}}{m}$ & $\bar{\tau}$ & $\begin{array}{l}\widetilde{J} \\
\stackrel{\gamma}{\mathcal{J}}\end{array}$ & $\begin{array}{c}\tilde{c} \\
\infty \\
\dot{m} \\
\dot{m}\end{array}$ & $\begin{array}{l}\bar{o} \\
\stackrel{丷}{\sim}\end{array}$ & $\begin{array}{l}\stackrel{a}{m} \\
\dot{\sigma}\end{array}$ & 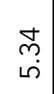 & $\begin{array}{l}\hat{N} \\
0\end{array}$ & 0 & 0 & 0 & $\begin{array}{l}\infty \\
\stackrel{\infty}{\complement} \\
\stackrel{\sigma}{\sigma}\end{array}$ & $\begin{array}{l}\stackrel{+}{\circ} \\
\infty \\
\infty\end{array}$ & $\frac{\infty}{\vdots}$ & $\begin{array}{l}\tilde{N} \\
\end{array}$ & $\stackrel{0}{0}$ & O̊. & $\stackrel{\circ}{\circ}$ \\
\hline$\frac{\frac{c}{4}}{\frac{m}{g}}$ & $\begin{array}{l}\stackrel{N}{N} \\
\dot{n}\end{array}$ & $\hat{\circ}$ & $\begin{array}{c}\vec{\sigma} \\
\stackrel{\infty}{q}\end{array}$ & $\begin{array}{l}\stackrel{a}{m} \\
\dot{m} \\
\dot{m}\end{array}$ & $\begin{array}{l}\stackrel{2}{0} \\
\alpha \\
\sigma\end{array}$ & $\begin{array}{l}\stackrel{a}{\hat{n}} \\
\dot{\alpha} \alpha\end{array}$ & $\begin{array}{c}\hat{\infty} \\
\dot{m}\end{array}$ & $\bar{m}$ & $\begin{array}{l}\tilde{N} \\
0 \\
0\end{array}$ & $\overline{0}$ & 0 & $\underset{\infty}{\stackrel{\infty}{\infty}}$ & $\begin{array}{c}N \\
\infty \\
\dot{\infty} \\
\infty\end{array}$ & $\begin{array}{l}\stackrel{+}{\dot{2}} \\
\stackrel{2}{\alpha}\end{array}$ & $\begin{array}{l}\text { Ju } \\
\dot{\sim} \\
\dot{0}\end{array}$ & $\stackrel{0}{\circ}$ & $\begin{array}{l}\stackrel{2}{0} \\
0 \\
0\end{array}$ & 0 \\
\hline$\overline{0}$ & $\alpha$ & $\begin{array}{l}n \\
0 \\
0 \\
0\end{array}$ & $\begin{array}{l}\stackrel{\infty}{+} \\
\text { ָ̦ }\end{array}$ & $\begin{array}{l}\stackrel{a}{m} \\
\stackrel{m}{m}\end{array}$ & $\begin{array}{l}\stackrel{\circ}{\circ} \\
\stackrel{+}{+}\end{array}$ & $\begin{array}{l}\hat{n} \\
\infty \\
\infty\end{array}$ & $\stackrel{\Re}{\leftarrow}$ & 0 & 0 & 0 & 0 & $\begin{array}{l}\stackrel{\infty}{\sim} \\
\stackrel{\infty}{\sim} \\
\stackrel{\infty}{N}\end{array}$ & 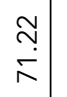 & $\begin{array}{l}m \\
o \\
\stackrel{\alpha}{\alpha}\end{array}$ & $\underset{\sim}{\sim}$ & $\begin{array}{l}\hat{O} \\
\dot{0}\end{array}$ & 0 & 0 \\
\hline $\begin{array}{l}\overline{\mathbb{O}} \\
\mathbf{0} \\
\stackrel{0}{\mathbf{J}} \\
\mathbf{Z}\end{array}$ & $\begin{array}{l}\stackrel{0}{+} \\
\dot{m}\end{array}$ & 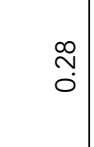 & 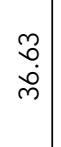 & 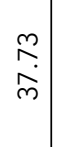 & $\begin{array}{l}\stackrel{\leftrightarrow}{\circ} \\
\dot{\bar{v}}\end{array}$ & $\begin{array}{l}\tilde{O} \\
\bar{\sigma} \\
\bar{\sigma}\end{array}$ & $\begin{array}{c}m \\
\infty \\
\infty\end{array}$ & $\begin{array}{l}\bar{\sigma} \\
0\end{array}$ & 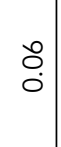 & $\begin{array}{l}\overline{0} \\
0\end{array}$ & $\begin{array}{c}\overline{0} \\
\end{array}$ & 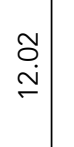 & $\begin{array}{l}\infty \\
\stackrel{\infty}{0} \\
\infty \\
\infty\end{array}$ & $\begin{array}{l}N \\
\stackrel{N}{\infty} \\
\infty\end{array}$ & $\begin{array}{l}\stackrel{0}{0} \\
\stackrel{ }{\simeq}\end{array}$ & $\underset{\sigma}{-}$ & $\stackrel{m}{\circ}$ & O̊. \\
\hline & $\begin{array}{c}\stackrel{0}{\mathfrak{z}} \\
\stackrel{5}{\mathbf{g}} \\
\stackrel{.}{z}\end{array}$ & 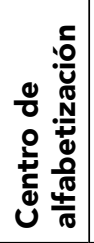 & 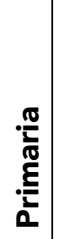 & 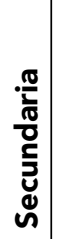 & 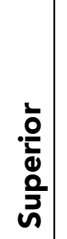 & 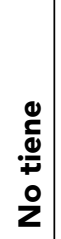 & $r$ & $\mathbf{N}$ & $m$ & $\boldsymbol{\sigma}$ & in & 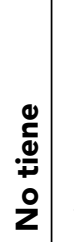 & $\underset{\stackrel{\boldsymbol{\Xi}}{\mathbf{\Xi}}}{\stackrel{\boldsymbol{E}}{\boldsymbol{E}}}$ & 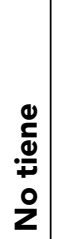 & $r$ & $\mathbf{N}$ & $m$ & $\theta$ \\
\hline & & 2 & :0 & & & & & & & & & 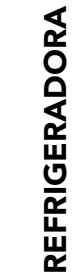 & 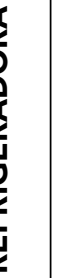 & & & $\begin{array}{l}n \\
0 \\
\frac{0}{b} \\
\frac{1}{5}\end{array}$ & & \\
\hline
\end{tabular}




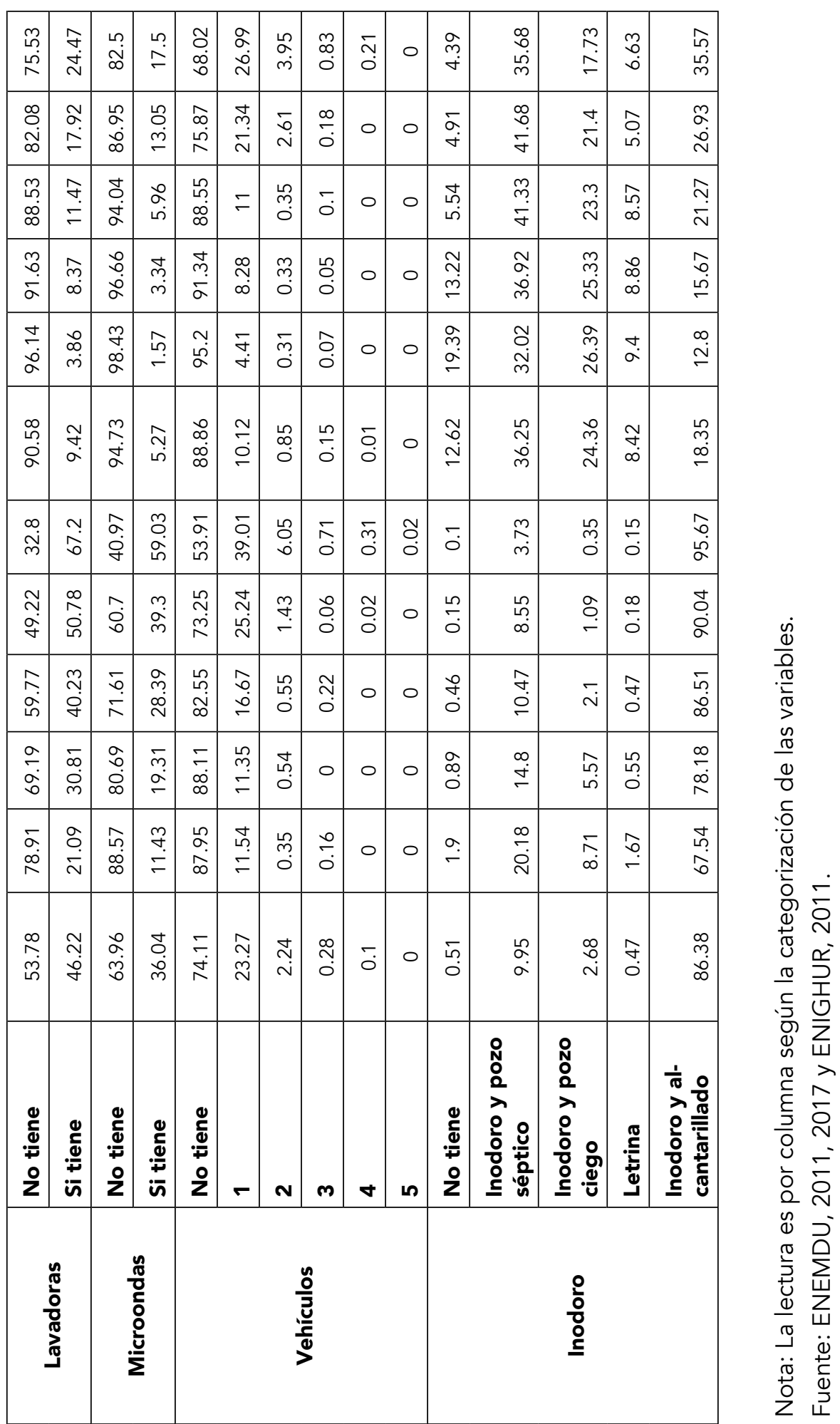

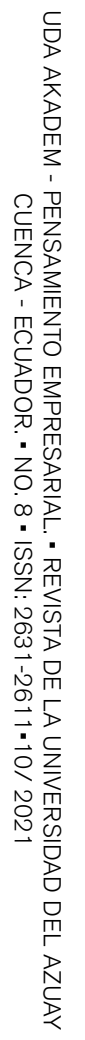




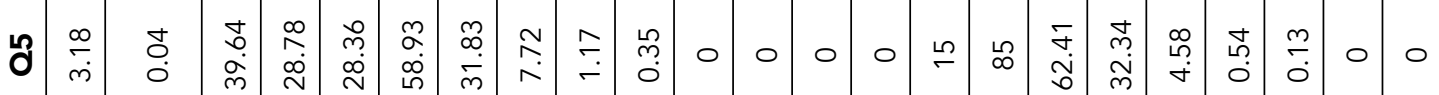

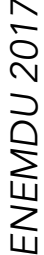

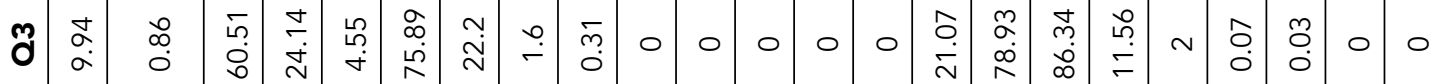
e

के

$\frac{1}{0}$

is

$\frac{\sqrt{2}}{\frac{2}{2}}$

足 $\overline{\mathrm{c}}$

\begin{tabular}{|c|c|c|c|c|c|c|c|c|c|c|c|c|c|c|c|c|c|c|c|c|c|c|c|c|c|}
\hline $\begin{array}{l}\stackrel{\circ}{\stackrel{P}{ \pm}} \\
\dot{ \pm}\end{array}$ & \begin{tabular}{l}
\multirow{J}{0}{} \\
0
\end{tabular} & 0 & 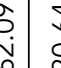 & 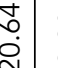 & & & $\stackrel{n}{\sim}$ & స & $\stackrel{v}{-}$ & s. & 0 & 0 & $c$ & 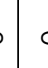 & D & 0 & ○ & & & & ${ }_{\infty}^{\infty}$ & & & & 0 \\
\hline
\end{tabular}

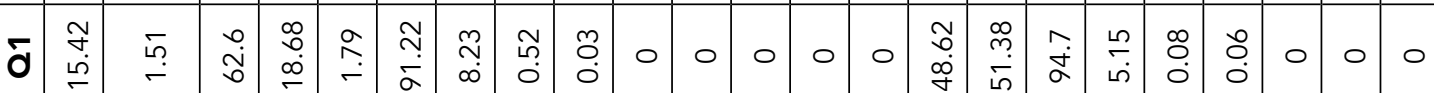

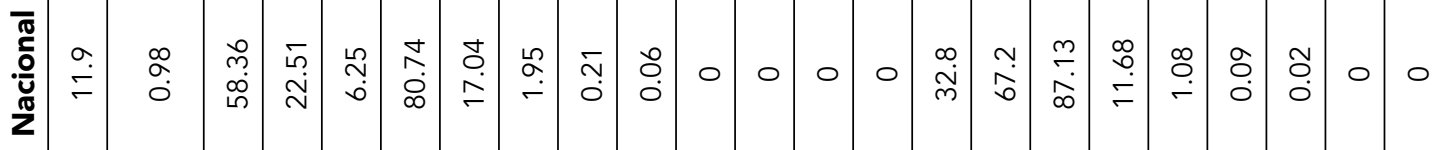
高

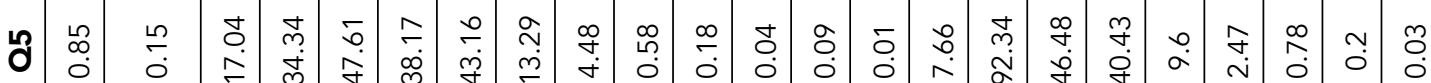

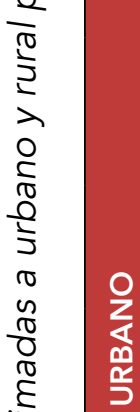

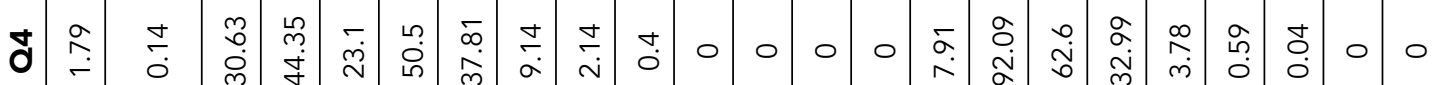

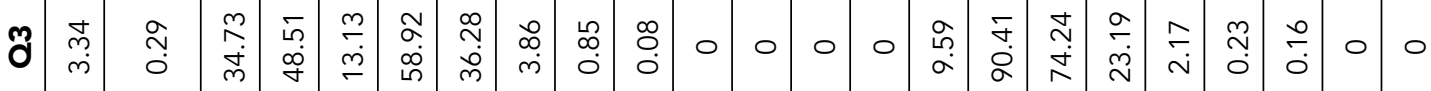

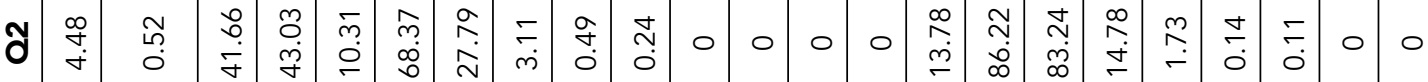

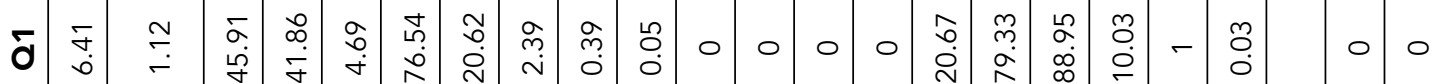

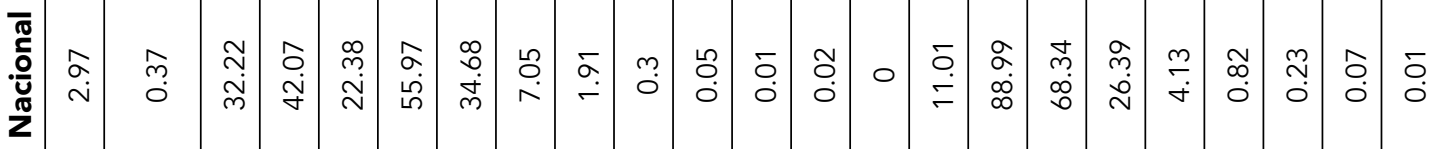

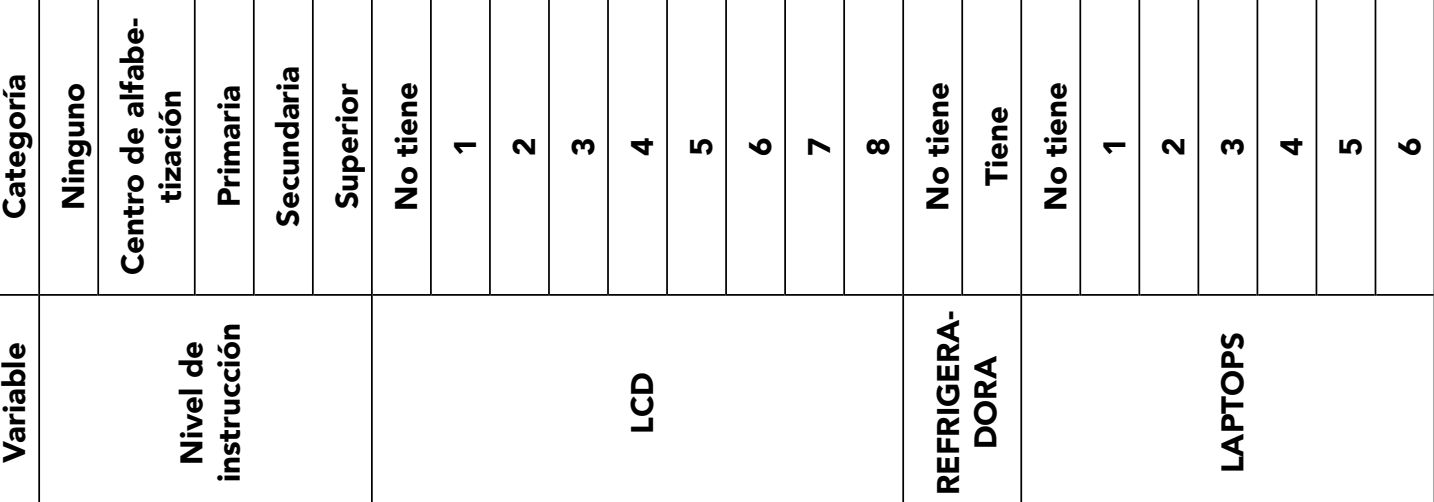




\begin{tabular}{|c|c|c|c|c|c|c|c|c|c|c|c|c|c|c|}
\hline $\begin{array}{l}a \\
0 \\
\text { în } \\
\text { ñ }\end{array}$ & $\begin{array}{l}\bar{m} \\
\dot{q}\end{array}$ & 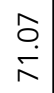 & $\begin{array}{l}m \\
a \\
\infty \\
\sim\end{array}$ & $\begin{array}{l}\frac{1}{n} \\
\bar{\sigma}\end{array}$ & $\begin{array}{l}\stackrel{v}{m} \\
\stackrel{m}{m}\end{array}$ & $\stackrel{\infty}{\leftarrow i}$ & $\begin{array}{l}m \\
0 \\
0\end{array}$ & $\begin{array}{l}\infty \\
\stackrel{0}{0} \\
0\end{array}$ & 0 & $\underset{m}{m}$ & 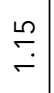 & \begin{tabular}{l}
$\infty$ \\
\hdashline \\
\end{tabular} & $\underset{m}{\stackrel{N}{m}}$ & $\underset{\text { }}{\tilde{N}}$ \\
\hline $\begin{array}{l}\text { mo } \\
\text { o. }\end{array}$ & $\begin{array}{l}\hat{m} \\
\stackrel{m}{m}\end{array}$ & $\begin{array}{l}\infty \\
\infty \\
\end{array}$ & 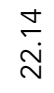 & $\begin{array}{l}0 \\
\stackrel{1}{\pi} \\
\frac{1}{n}\end{array}$ & 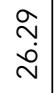 & $\stackrel{\Sigma}{\check{r}}$ & $\begin{array}{l}m \\
0 \\
0\end{array}$ & 0 & 0 & 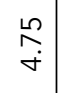 & $\begin{array}{l}\infty \\
\sim \\
m\end{array}$ & $\begin{array}{l}\stackrel{0}{\hat{0}} \\
\stackrel{0}{\circ}\end{array}$ & $\begin{array}{l}\alpha \\
\alpha \\
\dot{0}\end{array}$ & $\stackrel{\sim}{\forall}$ \\
\hline ㄱ & ஓ & $\begin{array}{l}a \\
\\
\infty \\
\infty\end{array}$ & 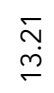 & $\begin{array}{c}m \\
\dot{L} \\
\infty\end{array}$ & $\begin{array}{l}\infty \\
\infty \\
\dot{m} \\
\dot{p}\end{array}$ & $\begin{array}{l}\bar{\infty} \\
0 \\
0\end{array}$ & 0 & 0 & 0 & $\begin{array}{l}\stackrel{2}{ } \\
\text { d }\end{array}$ & $\underset{\sim}{\stackrel{\sim}{n}}$ & $\stackrel{\stackrel{n}{\check{I}}}{\stackrel{\longrightarrow}{\leftarrow}}$ & $\begin{array}{l}0 \\
\text { o. } \\
\dot{\sigma}\end{array}$ & 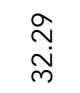 \\
\hline 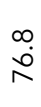 & $\stackrel{\sim}{\sim}$ & $\begin{array}{l}\infty \\
\hat{\alpha} \\
\alpha\end{array}$ & $\underset{N}{N}$ & $\begin{array}{l}\tilde{m} \\
\stackrel{2}{ }\end{array}$ & 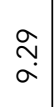 & 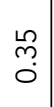 & $\begin{array}{l}\dot{0} \\
\stackrel{0}{0} \\
\end{array}$ & 0 & 0 & $\begin{array}{l}\mathcal{Y} \\
\text { b. }\end{array}$ & $\stackrel{\curvearrowright}{\dot{\sigma}}$ & 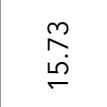 & $\begin{array}{l}\bar{\sigma} \\
\infty \\
\infty \\
+\end{array}$ & $\begin{array}{l}\stackrel{L}{\leftrightarrow n} \\
\stackrel{\sim}{\sim}\end{array}$ \\
\hline $\begin{array}{l}a \\
\dot{0} \\
\infty\end{array}$ & $\stackrel{\bar{m}}{=}$ & $\begin{array}{l}a \\
a \\
\alpha \\
\alpha\end{array}$ & $\stackrel{\bar{m}}{i}$ & $\begin{array}{l}\stackrel{+}{m} \\
\stackrel{m}{ }\end{array}$ & 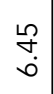 & $\stackrel{\llcorner}{\check{0}}$ & $\begin{array}{l}\circ \\
0 \\
0\end{array}$ & 0 & 0 & $\begin{array}{l}\overline{0} \\
\dot{0}\end{array}$ & $\stackrel{n}{\sim}$ & $\stackrel{a}{\stackrel{0}{\prime}}$ & $\begin{array}{l}m \\
\infty \\
\stackrel{m}{m} \\
\text { m. }\end{array}$ & $\begin{array}{l}\stackrel{0}{2} \\
\infty \\
\infty\end{array}$ \\
\hline Nָ & $\begin{array}{l}\stackrel{\infty}{\sim} \\
\stackrel{\dot{d}}{\sim}\end{array}$ & $\begin{array}{l}0 \\
0 \\
\infty \\
\infty\end{array}$ & 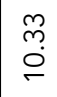 & 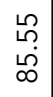 & $\stackrel{\vec{r}}{\stackrel{m}{r}}$ & $\begin{array}{l}\stackrel{\sim}{\alpha} \\
\stackrel{0}{0}\end{array}$ & $\begin{array}{l}0 \\
0 \\
0\end{array}$ & $\bar{\delta}$ & 0 & $\begin{array}{l}\stackrel{\sigma}{\sigma} \\
\sigma\end{array}$ & $\begin{array}{l}\text { Oे } \\
\text { in }\end{array}$ & $\begin{array}{l}\stackrel{\mathscr{H}}{+} \\
\stackrel{+}{\leftarrow}\end{array}$ & $\begin{array}{l}\infty \\
\stackrel{\infty}{\mathcal{V}} \\
\stackrel{y}{ }\end{array}$ & $\begin{array}{l}\stackrel{L}{\infty} \\
\infty \\
\infty \\
\sim\end{array}$ \\
\hline $\begin{array}{l}\widehat{\infty} \\
\infty \\
i\end{array}$ & $\stackrel{m}{\stackrel{m}{r}}$ & $\begin{array}{l}\stackrel{\sigma}{\grave{j}} \\
\underset{\gamma}{\mathrm{V}}\end{array}$ & 交 & 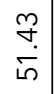 & $\begin{array}{l}\tilde{m} \\
\dot{q} \\
\dot{q}\end{array}$ & $\underset{N}{N}$ & $\stackrel{\hat{~}}{\hat{0}}$ & $\stackrel{m}{\check{c}}$ & $\frac{m}{\check{0}}$ & 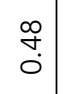 & $\begin{array}{c}- \\
\dot{0}\end{array}$ & $\stackrel{\stackrel{L}{m}}{\mathrm{~m}_{0}}$ & $\begin{array}{l}\stackrel{0}{\circ} \\
\infty\end{array}$ & $\stackrel{\circ}{\circ}$ \\
\hline $\begin{array}{l}\bar{a} \\
\text { ò } \\
\text { mat }\end{array}$ & 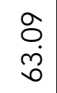 & $\begin{array}{l}a \\
\infty \\
a \\
\vdots \\
i n\end{array}$ & $\bar{\sigma}$ & $\begin{array}{l}m \\
\infty \\
\\
\end{array}$ & $\begin{array}{l}\hat{N} \\
\stackrel{D}{ }\end{array}$ & $\stackrel{\infty}{-}$ & $\begin{array}{l}20 \\
0 \\
0\end{array}$ & $\begin{array}{l}\text { Oे. } \\
\text { O. }\end{array}$ & 0 & $\begin{array}{c}\hat{i} \\
\hat{0}\end{array}$ & $\begin{array}{l}\infty \\
\stackrel{0}{0} \\
0\end{array}$ & $\underset{⿱}{\stackrel{J}{0}}$ & $\stackrel{\sim}{\simeq}$ & $\begin{array}{l}\bar{y} \\
\infty \\
\infty\end{array}$ \\
\hline $\begin{array}{l}\stackrel{\alpha}{\alpha} \\
\dot{\gamma}\end{array}$ & ¿ & $\stackrel{m}{\stackrel{m}{n}}$ & $\begin{array}{l}\hat{N} \\
\text { à }\end{array}$ & $\begin{array}{l}\stackrel{\sim}{m} \\
\underset{\infty}{i}\end{array}$ & 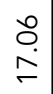 & $\begin{array}{l}\text { น̊n } \\
\text { Oे }\end{array}$ & $\begin{array}{l}m \\
0 \\
0\end{array}$ & 0 & 0 & $\begin{array}{l}\infty \\
\stackrel{0}{0} \\
0\end{array}$ & $\stackrel{\sim}{0}$ & 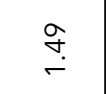 & 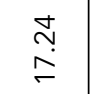 & $\begin{array}{l}\stackrel{\infty}{N} \\
\stackrel{\infty}{\infty}\end{array}$ \\
\hline in & $\begin{array}{l}\widetilde{N} \\
\text { o. } \\
\text { o }\end{array}$ & $\begin{array}{l}\bar{n} \\
\infty \\
\infty \\
\infty\end{array}$ & $\frac{q}{\dot{\tau}}$ & $\begin{array}{l}2 n \\
0 \\
i \\
\infty\end{array}$ & $\stackrel{\bar{m}}{\stackrel{\sim}{\sim}}$ & \begin{tabular}{l}
\multirow{2}{*}{} \\
$\stackrel{0}{0}$
\end{tabular} & 0 & 0 & 0 & $\stackrel{\leftrightarrow}{\stackrel{\leftrightarrow}{r}}$ & $\underset{⿱}{\stackrel{*}{\circ}}$ & 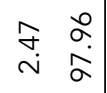 & $\begin{array}{l}\alpha \\
\infty \\
\sigma \\
\sigma\end{array}$ & $\begin{array}{l}\bar{\sigma} \\
\text { ம் }\end{array}$ \\
\hline$\frac{\bar{\sigma}}{\delta}$ & $\begin{array}{l}\alpha \\
\alpha \\
\infty \\
m\end{array}$ & \begin{tabular}{l}
\multirow{y}{v}{} \\
$\dot{L}$ \\
$\infty$
\end{tabular} & 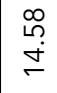 & $\begin{array}{l}\bar{n} \\
\infty \\
\infty \\
\end{array}$ & 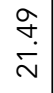 & 0 & 0 & 0 & 0 & $\stackrel{\infty}{-}$ & $\hat{o}$ & 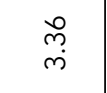 & 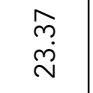 & 竞 \\
\hline 哭 & 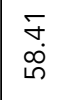 & $\begin{array}{l}\infty \\
\stackrel{\infty}{n} \\
\dot{j}\end{array}$ & ঙ̊. & $\stackrel{\stackrel{\sim}{m}}{\stackrel{N}{N}}$ & 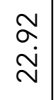 & 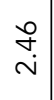 & $\underset{N}{0}$ & $\begin{array}{l}\dot{0} \\
0 \\
\dot{0}\end{array}$ & $\begin{array}{l}m \\
0 \\
0\end{array}$ & $\begin{array}{l}a \\
a \\
0\end{array}$ & $\stackrel{\sim}{\sim}$ & $\stackrel{\text { ঙ․ }}{\leftarrow}$ & $\begin{array}{l}\underset{N}{\sim} \\
\stackrel{\omega}{\sim}\end{array}$ & $\bar{\infty}$ \\
\hline 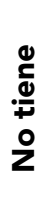 & 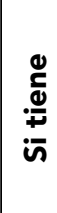 & 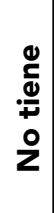 & 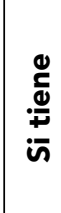 & 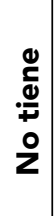 & $\sigma$ & $\mathbf{N}$ & m & $\nabla$ & Ln & 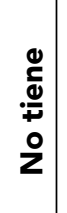 & 竞 & 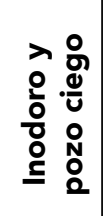 & 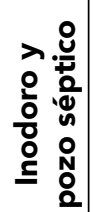 & 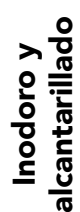 \\
\hline & f & & $\begin{array}{l}\frac{n}{\pi} \\
0 \\
0 \\
0 \\
0 \\
0\end{array}$ & \multicolumn{6}{|c|}{$\frac{\stackrel{n}{0}}{\frac{u}{c}}$} & \multicolumn{5}{|c|}{$\begin{array}{l}\stackrel{0}{0} \\
\frac{0}{0} \\
\stackrel{0}{\underline{0}}\end{array}$} \\
\hline
\end{tabular}
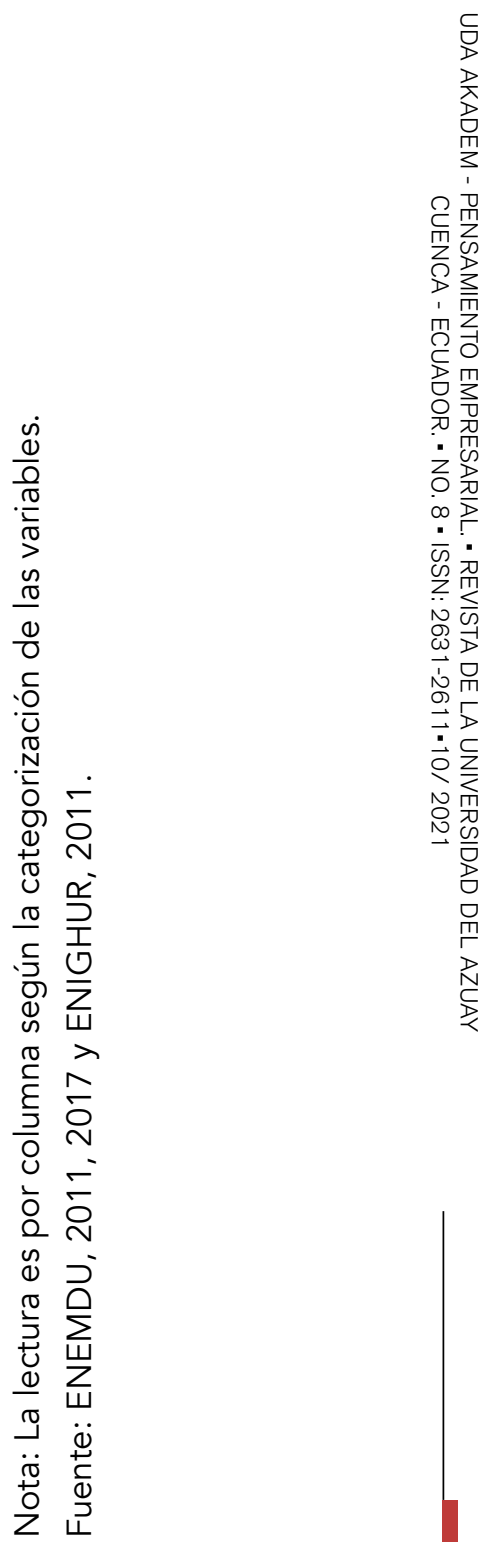
Tabla A.5. Variables incluidas y pesos obtenidos del primer componente bajo la técnica de análisis de componentes principales policórico

\begin{tabular}{|l|l|}
\hline & \multicolumn{1}{|c|}{$\begin{array}{c}\text { ENIGHUR } \\
\text { Valor propio }\end{array}$} \\
\hline Varianza explicada & 4,325 \\
\hline Instrucción del jefe del hogar & 0,541 \\
\hline Sin educación & $-0,670$ \\
\hline Centro de alfabetización & $-0,511$ \\
\hline Primaria & $-0,206$ \\
\hline Secundaria & 0,141 \\
\hline Universitaria & 0,483 \\
\hline LCD & \\
\hline Ninguno & $-0,033$ \\
\hline 1 & 0,611 \\
\hline 2 & 0,871 \\
\hline 3 & 1,044 \\
\hline 4 & 1,182 \\
\hline 5 & 1,276 \\
\hline 6 & \\
\hline 7 & \\
\hline 8 & $-0,455$ \\
\hline Refrigeradoras & 0,142 \\
\hline Ninguno & \\
\hline 1 & 0,096 \\
\hline Laptops & \\
\hline Ninguno & \\
\hline 1 & \\
\hline
\end{tabular}




\begin{tabular}{|l|l|}
\hline 2 & 0,935 \\
\hline 3 & 1,186 \\
\hline 4 & 1,413 \\
\hline 5 & \\
\hline 6 & \\
\hline Lavadoras & \\
\hline Ninguno & $-0,199$ \\
\hline 1 & 0,409 \\
\hline Microondas & \\
\hline Ninguno & $-0,154$ \\
\hline 1 & 0,529 \\
\hline Número de Vehículos & \\
\hline Ninguno & $-0,105$ \\
\hline 1 & 0,500 \\
\hline 2 & 0,866 \\
\hline 3 & 1,121 \\
\hline 4 & 1,298 \\
\hline 5 & 1,385 \\
\hline 6 & 1,475 \\
\hline Eliminación de Excreta & \\
\hline No tiene & $-0,670$ \\
\hline Letrina & $-0,495$ \\
\hline Inodoro y pozo ciego & $-0,400$ \\
\hline Inodoro y pozo séptico & $-0,214$ \\
\hline Inodoro y alcantarillado & 0,202 \\
\hline & \\
\hline 1 & \\
\hline & \\
\hline & \\
\hline & \\
\hline & \\
\hline & \\
\hline & \\
\hline & \\
\hline
\end{tabular}

Fuente: ENIGHUR, 2011 
Tabla A6: Correlación del nivel de ingresos con el índice de riqueza estandarizado. Nacional y por área

\begin{tabular}{|l|l|l|l|}
\hline & Nacional & Urbano & Rural \\
\hline $\begin{array}{l}\text { ENIGHUR } \\
\mathbf{2 0 1 1}\end{array}$ & 0.3894 & 0.353 & 0.4196 \\
\hline $\begin{array}{l}\text { ENEMDU } \\
\mathbf{2 0 1 1}\end{array}$ & 0.422 & 0.3816 & 0.3279 \\
\hline $\begin{array}{l}\text { ENEMDU } \\
\mathbf{2 0 1 7}\end{array}$ & 0.3465 & 0.3351 & 0.2531 \\
\hline
\end{tabular}

Fuente: ENEMDU, 2011, 2017 y ENIGHUR, 2011

Tabla A7: Porcentaje de hogares clasificados según quintil en base al Ingreso y al indicador de riqueza

\begin{tabular}{|c|c|c|}
\hline & \multicolumn{2}{|c|}{ ENIGHUR 2011 } \\
\hline Quintil & $\begin{array}{c}\text { Indicador riqueza } \\
\text { PCA policórico }\end{array}$ & $\begin{array}{c}\text { Indicador rique- } \\
\text { za PCA }\end{array}$ \\
\hline 1 & 0,183 & 0,131 \\
\hline 2 & 0,252 & 0,157 \\
\hline 3 & 0,300 & 0,177 \\
\hline 4 & 0,360 & 0,206 \\
\hline 5 & 0,486 & 0,277 \\
\hline Total & $\mathbf{0 , 3 1 2}$ & $\mathbf{0 , 1 8 2}$ \\
\hline
\end{tabular}

Fuente: ENIGHUR, 2011 
Tabla A8: Clasificación de hogares por quintiles según PCA policórico y compuesto

\begin{tabular}{|c|c|c|c|c|c|}
\hline \multirow{2}{*}{} & \multicolumn{5}{|c|}{ ENIGHUR 2011 } \\
\cline { 2 - 6 } $\begin{array}{c}\text { PCA } \\
\text { Policórico }\end{array}$ & $\mathbf{1}$ & $\mathbf{2}$ & $\mathbf{3}$ & $\mathbf{4}$ & $\mathbf{5}$ \\
\hline 1 & $\mathbf{8 1 \%}$ & $18 \%$ & $0 \%$ & $0 \%$ & $0 \%$ \\
\hline 2 & $28 \%$ & $49 \%$ & $23 \%$ & $0 \%$ & $0 \%$ \\
\hline 3 & $0 \%$ & $40 \%$ & $45 \%$ & $15 \%$ & $0 \%$ \\
\hline 4 & $0 \%$ & $0 \%$ & $21 \%$ & $73 \%$ & $6 \%$ \\
\hline 5 & $0 \%$ & $0 \%$ & $0 \%$ & $10 \%$ & $\mathbf{9 0 \%}$ \\
\hline
\end{tabular}

Fuente: ENIGHUR, 2011

Tabla A9: Porcentaje de personas según clasificación de quintiles según metodología por PCA y medición del ingreso percápita. Área urbana y rural 


\begin{tabular}{|c|c|c|c|c|c|c|c|c|c|c|}
\hline & \multicolumn{5}{|c|}{ ENEMDU 2011} & \multicolumn{5}{|c|}{ ENEMDU 2017} \\
\hline & \multicolumn{10}{|c|}{ Ingresos per cápita } \\
\hline & \multicolumn{10}{|c|}{ Área: Urbana } \\
\hline $\begin{array}{l}\text { Poli- } \\
\text { córico }\end{array}$ & 1 & 2 & 3 & 4 & 5 & 1 & 2 & 3 & 4 & 5 \\
\hline 1 & $41 \%$ & $27 \%$ & $18 \%$ & $10 \%$ & $5 \%$ & $39 \%$ & $26 \%$ & $19 \%$ & $10 \%$ & $5 \%$ \\
\hline 2 & $27 \%$ & $27 \%$ & $23 \%$ & $15 \%$ & $8 \%$ & $28 \%$ & $26 \%$ & $22 \%$ & $14 \%$ & $9 \%$ \\
\hline 3 & $18 \%$ & $22 \%$ & $26 \%$ & $18 \%$ & $15 \%$ & $19 \%$ & $23 \%$ & $23 \%$ & $21 \%$ & $13 \%$ \\
\hline 4 & $9 \%$ & $16 \%$ & $26 \%$ & $25 \%$ & $24 \%$ & $8 \%$ & $17 \%$ & $21 \%$ & $28 \%$ & $26 \%$ \\
\hline 5 & $3 \%$ & $8 \%$ & $15 \%$ & $24 \%$ & $50 \%$ & $4 \%$ & $8 \%$ & $15 \%$ & $27 \%$ & $47 \%$ \\
\hline \multirow[t]{2}{*}{ Total } & $20 \%$ & $20 \%$ & $22 \%$ & $18 \%$ & $20 \%$ & $20 \%$ & $20 \%$ & $20 \%$ & $20 \%$ & $20 \%$ \\
\hline & \multicolumn{10}{|c|}{ Área: Rural } \\
\hline 1 & $32 \%$ & $24 \%$ & $20 \%$ & $13 \%$ & $11 \%$ & $36 \%$ & $25 \%$ & $20 \%$ & $11 \%$ & $8 \%$ \\
\hline 2 & $25 \%$ & $21 \%$ & $23 \%$ & $16 \%$ & $15 \%$ & $26 \%$ & $25 \%$ & $22 \%$ & $16 \%$ & $10 \%$ \\
\hline 3 & $19 \%$ & $21 \%$ & $23 \%$ & $20 \%$ & $18 \%$ & $19 \%$ & $23 \%$ & $24 \%$ & $20 \%$ & $14 \%$ \\
\hline 4 & $15 \%$ & $18 \%$ & $24 \%$ & $25 \%$ & $19 \%$ & $11 \%$ & $18 \%$ & $23 \%$ & $26 \%$ & $21 \%$ \\
\hline 5 & $8 \%$ & $11 \%$ & $18 \%$ & $22 \%$ & $41 \%$ & $5 \%$ & $9 \%$ & $15 \%$ & $24 \%$ & $48 \%$ \\
\hline Total & $21 \%$ & $19 \%$ & $21 \%$ & $19 \%$ & $20 \%$ & $20 \%$ & $20 \%$ & $21 \%$ & $19 \%$ & $20 \%$ \\
\hline
\end{tabular}

Fuente: ENEMDU 2011 y 2017.

Figura A1. Distribución de índice PCA policórico
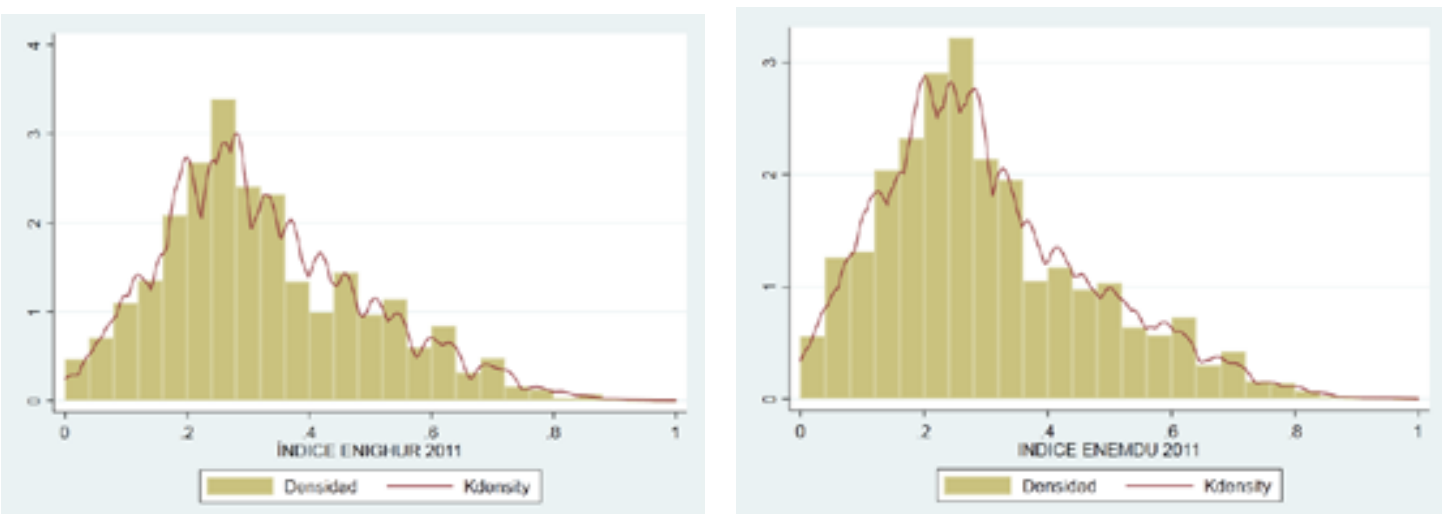


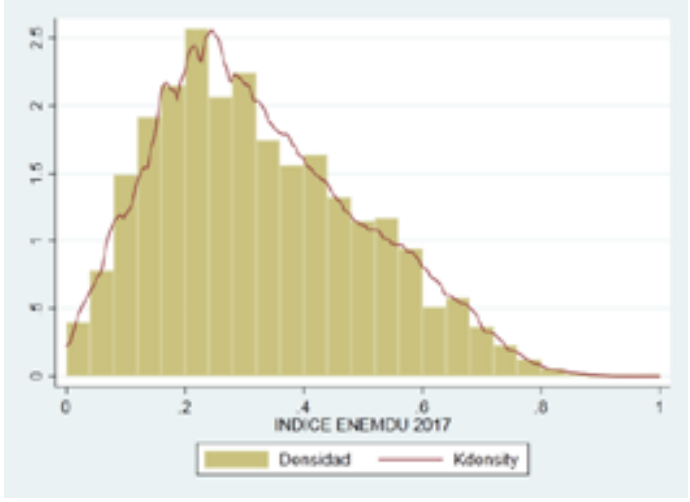

Fuente: ENEMDU, 2011, 2017 y ENIGHUR, 2011

Figura A2. Índice de Riqueza Estandarizado. A nivel nacional y por área de ubicación

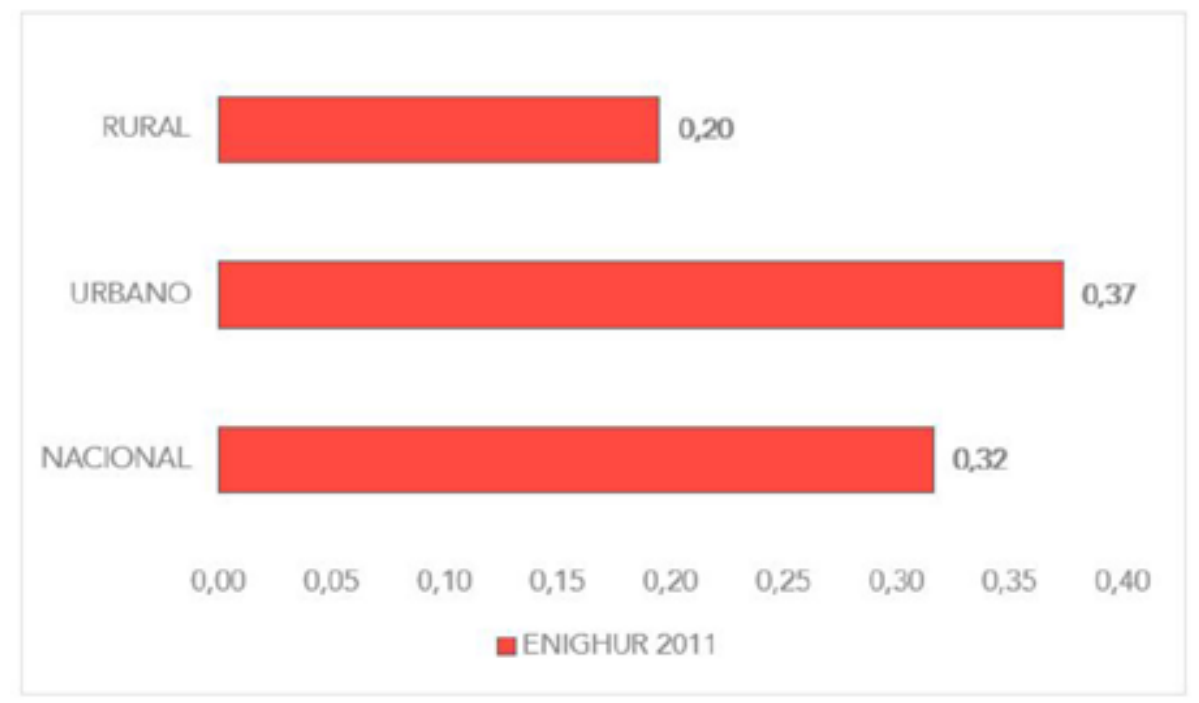

Fuente: ENIGHUR, 2011 
Figura A3. Índice de desigualdad de Gini 2011 y 2017

PCA policórico ENEMDU 2011

PCA ENEMDU 2011

PCA policórico ENEMDU 2017

PCA ENEMDU 2017

PCA policorico ENIGUR 2011

PCA ENIGHUR 2011

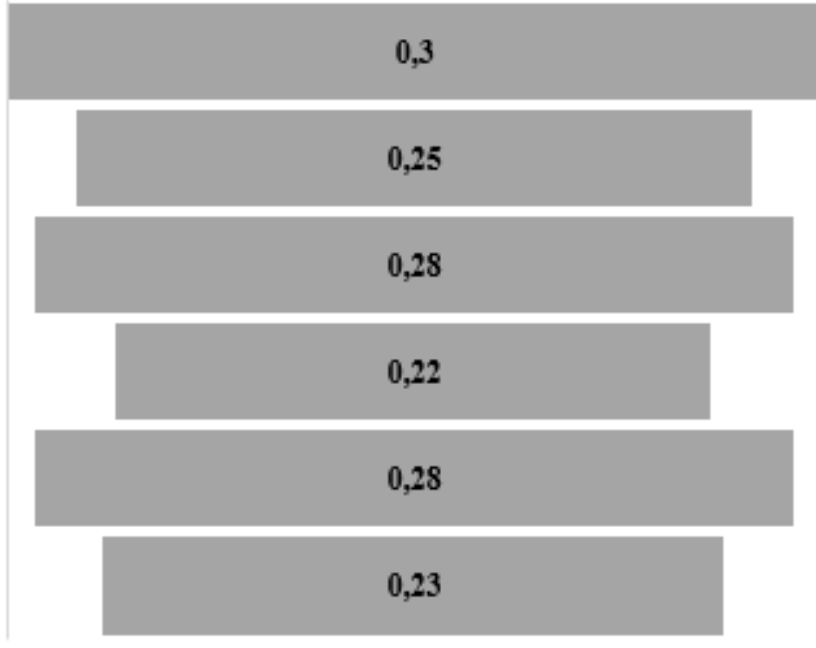

Fuente: ENEMDU, 2011, 2017 y ENIGHUR, 2011

Figura A2: Nivel de desigualdad medida por el índice de riqueza Policórico y el Ingreso percápita
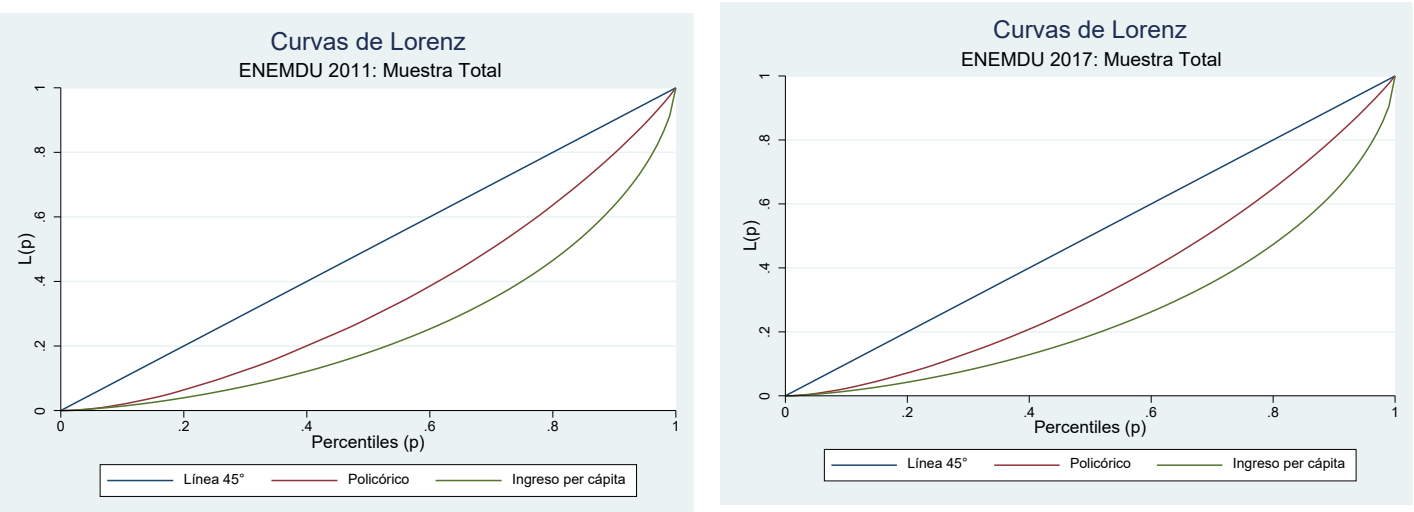

Fuente: ENEMDU 2011 y 2017. 
Figura A3: Nivel de desigualdad medida por índice de riqueza policórico y el ingreso percápita a nivel de área urbana y rural, periodo 2011

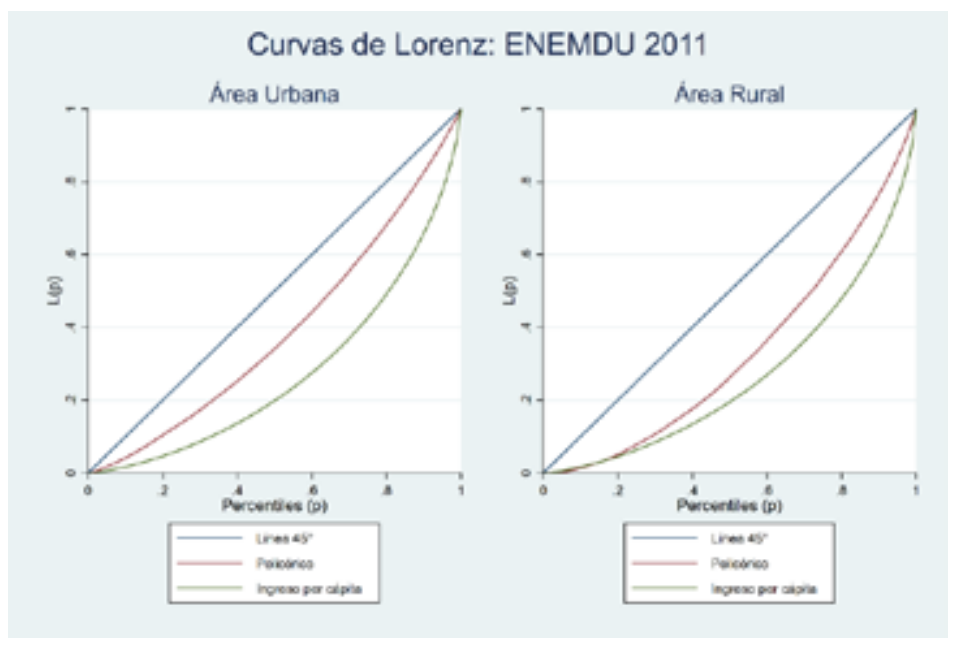

Fuente: ENEMDU 2011 y 2017.

Figura A4: Nivel de desigualdad medida por índide de riqueza Policórico y el Ingreso percápita a nivel de área urbana y rural, periodo 2017

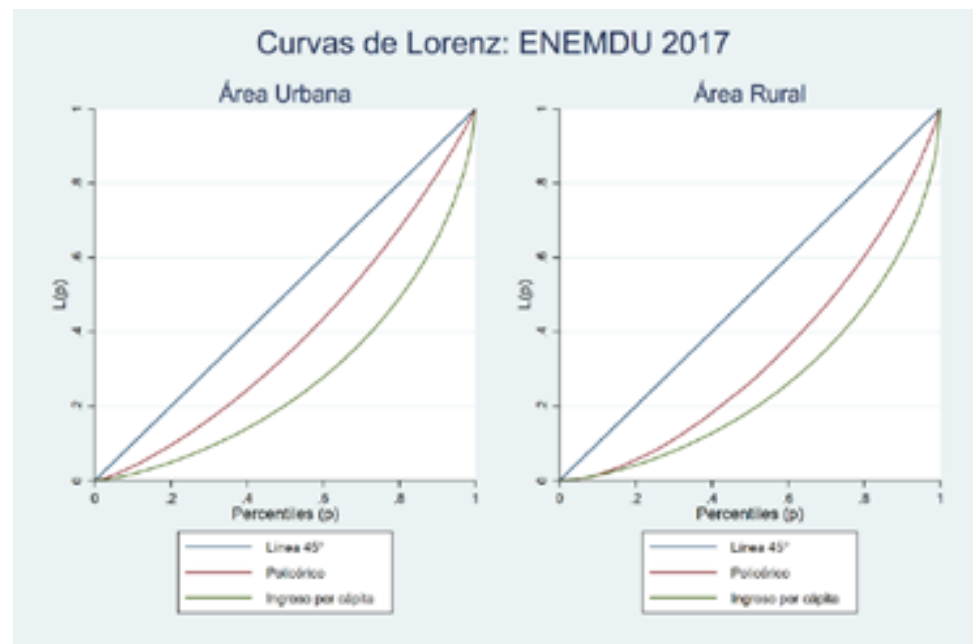

Fuente: ENEMDU 2011 y 2017. 